\title{
A gestão da mudança em ambientes dinâmicos: um estudo no setor das telecomunicações
}

\section{Change management in dynamic environments: a study in the telecommunications industry}

Maria Cristina Zampieri Sellmann ${ }^{1}$

Reynaldo Cavalheiro Marcondes ${ }^{2}$

\begin{abstract}
Resumo
Este artigo busca entender como a gestão da mudança é realizada em ambientes de negócios altamente dinâmicos. Está fundamentado em pesquisa exploratória na qual se utilizou a análise de conteúdo como procedimento metodológico qualitativo. Foi aplicada a entrevista em profundidade junto a oito executivos das empresas Siemens, Motorola e Ericsson, envolvidos em processos de mudança. Os resultados revelaram ter havido poucas divergências ou variações entre as práticas de gestão da mudança nas três empresas dos entrevistados; não ter ocorrido todos os passos essenciais ao processo de mudança de maneira explícita conforme preconiza a literatura, não obstante o sucesso obtido por essas empresas na implementação das mudanças; a emergência do senso de urgência e da coalizão administrativa, aspectos não tratados na literatura levantada; e o envolvimento das pessoas como consequência dos treinamentos e da troca de informações promovidos durante a execução do projeto.
\end{abstract}

Palavras-chaves: gestão da mudança - processo de mudança - relações interpessoais - telecomunicações

\section{Abstract}

This article seeks to understand how change management takes place in highly dynamic business environments. It is based on exploratory research in which the content analysis procedure as a qualitative method was used. In-depth interviews were conducted with executives from eight companies linked to Siemens, Motorola and Ericsson, involved in processes of change. The results revealed that there have been few changes or differences between the practices of change management in the three companies of the respondents; nor have all the essential steps in the process of change as explicitly advocated by the literature taken place. Despite the success achieved by these companies in implementing changes, the emergence of a sense of urgency and coalition in administrative issues addressed in the literature has not taken place, along with the involvement of people as a result of training and exchange of information promoted during project execution.

\section{Introdução}

Este artigo trata da gestão da mudança como um recurso estratégico de organizações que atuam com elevada complexidade e restrições em sua estrutura, sendo assim, um meio importante para manutenção da competitividade organizacional.

O cenário de constantes transformações no qual as empresas estão inseridas (KIRKBRIDGE, 1998; ANDERSON; ANDERSON, 2001) tem ressaltado a importância estratégica da prática continuada da gestão da mudança no intuito de transformar os desafios gerados pela globalização, rápidos avanços tecnológicos e

\footnotetext{
Submetido em dezembro de 2009 e aceito em março de 2010.

${ }^{1}$ Mestre em Administração de Empresas pela Universidade Presbiteriana Mackenzie. Gerente de Strategic Sourcing na Ericsson Brasil. Endereço: Rua Maria Prestes Maia, 300 - Vila Guilherme - Cep 02047-901 São Paulo - SP, , tel. :11- 6224-1614. E-mail mariacristina.sellmann@bol.com.br

2 Doutor em Administração de Empresas pela USP. Professor Titular do Centro de Ciências Sociais e Aplicadas e membro permanente do Programa de Pós-Graduação em Administração da Universidade Presbiteriana Mackenzie, Rua da Consolação, 930 - Prédio 29 - sala G - Cep $01302-907$ São Paulo SP, tel.: 11-2114-8248. E-mail reynaldo@mackenzie.br,
} 
aumento da competitividade, em oportunidades (KOTTER, 2000). Isso inclui a execução de um conjunto de atividades que permitam a pró-ação e o ajuste das organizações para modificarem significativamente suas circunstâncias de forma eficiente e eficaz.

Sims e Mea (2002) definem a gestão da mudança como práticas gerenciais para adaptação às novas realidades de negócio. Kotter (2001), por meio do exame de algumas histórias de empresas de sucesso, revela que a gestão da mudança é crucial para a manutenção da prosperidade e competitividade, pois minimiza os riscos e maximiza as oportunidades relacionadas ao processo de transformação.

Em artigo publicado pela revista Info Corporate, Terzian (2004) afirma que a gestão da mudança é "considerada peça fundamental para a saúde de qualquer companhia, não importa seu tamanho ou setor de atuação, e tem como tarefa implementar procedimentos e técnicas capazes de acompanhar o desenvolvimento do negócio".

Pelas razões expostas, está se tornando cada vez mais comum e estratégico para as organizações a existência de equipes permanentes voltadas para a gestão da mudança (ANDERSON; ANDERSON, 2001). Segundo Adizes (1995), a gestão da mudança vem pré-dispondo e preparando as organizações para as transformações, melhorando, sobretudo, sua eficiência.

De maneira simplificada, a gestão da mudança é basicamente realizada por meio do gerenciamento e execução de diversas fases do processo de mudança com a consideração das questões interpessoais.

Tushman e Anderson (1986) afirmam que constantes mudanças fazem parte do cotidiano de empresas que desejam se manter competitivas, sendo natural a existência de oportunidades e riscos relacionados a esse processo.

Embora a gestão da mudança venha sendo amplamente estudada, há ainda boas oportunidades de aprendizado, particularmente em situações onde há a introdução de novos processos como um único bloco ou "pacote" com a expectativa destes se tornarem um recurso estratégico para desenvolver e reforçar a competitividade da empresa no mercado dos seus produtos.

Para este artigo optou-se por abordar a gestão da mudança provocada pela adoção do Regime Aduaneiro de Entreposto Industrial sob Controle Informatizado - Recof pelas empresas, com o objetivo de obterem vantagens competitivas nos seus negócios de exportação, que enfrentam acirrada competição de mercado. $\mathrm{O}$ referido regime é um incentivo fiscal que implica mudança profunda de processos internos das empresas que o adotam, conforme será detalhado mais adiante neste artigo.

Assim, com a intenção de entender como a gestão da mudança é realizada em ambientes de negócios altamente dinâmicos, foram definidos três objetivos para este artigo:

1. identificar os aspectos relevantes envolvidos na gestão da mudança em ambientes dinâmicos como o das telecomunicações;

2. evidenciar as fases do processo de mudanças realizados no ambiente interno desse tipo de empresas em decorrência da adoção do Recof;

3. conhecer como as questões interpessoais foram tratadas durante a implementação dessas mudanças.

\section{Referencial teórico}

Neste item estão apresentados os conceitos sobre gestão da mudança, processo de mudança e seus aspectos interpessoais, com a intenção de se ter a fundamentação necessária para a análise dos resultados deste estudo. 


\section{Gestão da mudança}

A gestão da mudança é apontada como um caminho para o ajuste eficaz das organizações aos novos cenários (ADIZES, 1995) (KIRKBRIDGE, 1998) (KOTTER, 1999, 2000, 2001) (NADLER; TUSHMAN, 2001) (ANDERSON; ANDERSON, 2001) (HAYES, 2002) (SIMS, 2002). Segundo Anderson e Anderson (2001), a gestão da mudança, desde a década de 90, vem assumindo papel de destaque entre as práticas gerenciais, pois prepara as corporações para novas realidades, uma vez que mudar tornou-se requisito para o sucesso, transformando os desafios da mudança em oportunidades.

Para Hayes (2002), a gestão da mudança está associada à modificação ou transformação da organização, visando manter ou melhorar sua eficácia por meio do gerenciamento, face aos processos de mudança. Assim, corrobora a posição de Adizes (1995) no que tange à contribuição da gestão da mudança para a eficiência e eficácia da organização.

Anderson e Anderson (2001) colocam que a gestão de uma mudança deve ter em seu escopo três elementos fundamentais: conteúdo, pessoas e processo. 1) Conteúdo - "o que" da organização precisa ser mudado, ou seja, a estratégia, a estrutura, os sistemas, os processos, as tecnologias, as práticas de trabalho, etc. 2) Pessoas comportamentos, emoções, mentes, e espíritos dos seres humanos que estão desenhando, implementando, suportando ou sendo impactados pela mudança.

3) Processo - "como" as mudanças no conteúdo e nas pessoas são planejadas, desenhadas e implementadas. Em outras palavras, o processo engloba as ações que produzirão as mudanças no conteúdo e nas pessoas.

A gestão da mudança, segundo Hayes (2002), se concentra no entendimento e execução do processo de mudança, ou seja, em definir "como" será realizada a mudança (processo) e em identificar "o que" precisa ser mudado (conteúdo). Também trata, durante todo o processo de mudança, das questões interpessoais (pessoas), tais como, a comunicação, a motivação, entre outras. Assim, corrobora a opinião de Anderson e Anderson (2001) no que tange ao alinhamento entre conteúdo, pessoas e processo, sendo que o foco principal está na execução do processo da mudança.

Muitos modelos conceituais desse processo foram desenvolvidos (SMEDS, 1994) (ADIZES, 1995) (KIRKBRIDGE, 1998) (KOTTER, 2000) (ANDERSON; ANDERSON, 2001) (QUATRO; HOEKSTRA; GILLEY, 2002) (HAYES, 2002), porém, no seu sentido mais amplo, pode ser definido como um framework conceitual composto por um conjunto de fases cujo objetivo é auxiliar o ajuste da empresa em ambientes de transformações.

Considerando que a mudança é um processo contínuo e não um destino (ANDERSON; ANDERSON, 2001), o maior desafio da gestão da mudança está no fato de que não existe cálculo explícito para introdução de mudanças nas empresas, pois, as circunstâncias nas quais estas estão inseridas são específicas. Entretanto, o ensinamento mais genérico dos casos de maior êxito revela que a gestão da mudança por meio do gerenciamento do processo de mudança e das suas questões interpessoais (pessoas, processo e conteúdo) é um caminho para se obter êxito em transformações (KOTTER, 1999, 2000) (HAYES, 2002) (SIMS, 2002).

\section{Processo de mudança}

Os modelos de processo apresentados a seguir têm a intenção de expor alguns desenvolvimentos teóricos dos frameworks concentuais relevantes para a realização da gestão da mudança nas organizações (KOTTER, 1999, 2000) (HAYES, 2002) (SIMS, 2002). Anderson e Anderson (2001) definem os modelos de processo de mudança como ferramentas de pensamento consciente, orientados para a ação e os resultados, por meio do gerenciamento das atividades da mudança visando à obtenção dos resultados esperados ao longo do tempo.

Smeds (1994), com base em estudos sobre empresas que adotaram a manufatura enxuta, sugere que o processo de mudança acontece por meio de fases, cujo início ocorre com a percepção da necessidade de mudança. Uma vez identificada a necessidade, faz-se necessário: 1) a execução das fases de análise e modelagem da situação 
corrente, 2) visualização da situação corrente e identificação de problemas e oportunidades, 3) definição da situação futura, 4) implementação da mudança e 5) estabilização do novo processo.

Hayes (2002) afirma que a mudança é muitas vezes gerenciada de forma menos eficiente do que poderia ser, porque alguns aspectos do processo de mudança não são levados em consideração por algumas empresas. Assim, na busca pelo aumento da eficiência organizacional, o autor apresenta os passos que considera essenciais em um processo com esse fim. Os passos descritos por Hayes (2002) estão representados em forma de fluxo na Figura 1.

\section{Figura 1- Passos no processo de mudança}

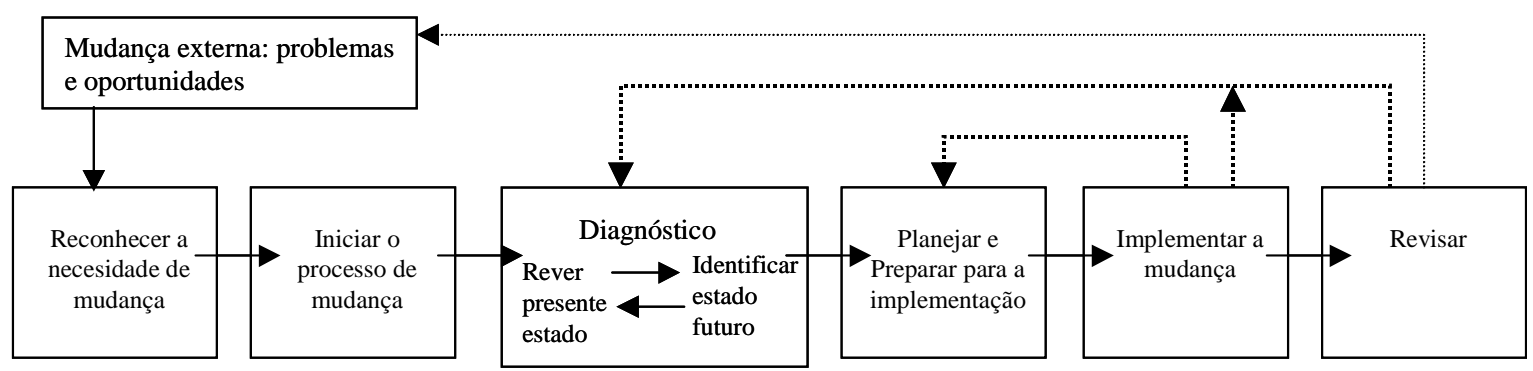

Fonte: Hayes (2002, p. 54) (tradução dos autores)

Passo 1 - Reconhecimento da necessidade de mudança: identificação de um evento externo ou circunstâncias internas que exigem alguma mudança (ADIZES, 1995) (KIRKBRIDGE, 1998) (STICKLAND, 1998) (ANDERSON; ANDERSON, 2001).

Passo 2 - Início do processo de mudança: tradução da necessidade de mudança em um desejo de mudança, com a definição de quem irá gerenciá-lo (STICKLAND, 1998) (HOAG; RITSCHARD; COOPER, 2002) para se estabelecer um relacionamento de confiança efetivo. Envolve uma revisão ou um estudo da viabilidade. Nessa fase é que se inicia o processo de descongelamento das resistências das pessoas e a aceitação da mudança (HAYES, 2002).

Passo 3 - Diagnóstico: análise da situação existente e identificação da situação futura (STICKLAND, 1998) (ANDERSON; ANDERSON, 2001) (SIMS; SIMS, 2002) (SENGE, 2004). Essa revisão ajuda a identificar a mudança por meio do diagnóstico da causa do problema, identificando deficiências correntes ou clarificando oportunidades, e auxilia na definição da situação futura desejada (HAYES, 2002).

Passo 4 - Preparação e planejamento para a implementação: construção de planos de ação visando retirar a empresa do estado presente para um estado futuro, para que a mudança proposta se concretize.

Passo 5 - Implementação da mudança: execução do plano de ação, elaborado na fase quatro, sendo necessário o monitoramento e controle constantes visando assegurar que as coisas estejam acontecendo conforme planejadas (ADIZES, 1995) (KIRKBRIDGE, 1998) (STICKLAND, 1998) (ANDERSON; ANDERSON, 2001) (SIMS; SIMS, 2002) (HOAG; RITSCHARD; COOPER, 2002) (SENGE, 2004).

Passo 6 - Revisão e consolidação: revisão dos resultados obtidos na implementação (lesson learned) e a consolidação da situação futura através de sistemas de feedback e recompensas (ADIZES, 1995) (KOTTER, 1999, 2000, 2001) (ANDERSON; ANDERSON, 2001) (SIMS; SIMS, 2002). Além da consolidação do novo estado, este passo envolve a construção e atualização de mudanças sempre que necessário, iniciando o ciclo do processo de mudança (HAYES, 2002).

Na Figura 2 está apresentado um fluxograma do modelo proposto por Kotter (2000), cujos conceitos relacionados às fases são similares aos conceitos propostos pelos outros autores, diferenciando-se muito pouco na nomenclatura, sequência e número de fases. 


\section{Figura 2 - O processo em oito etapas da criação de uma grande mudança}

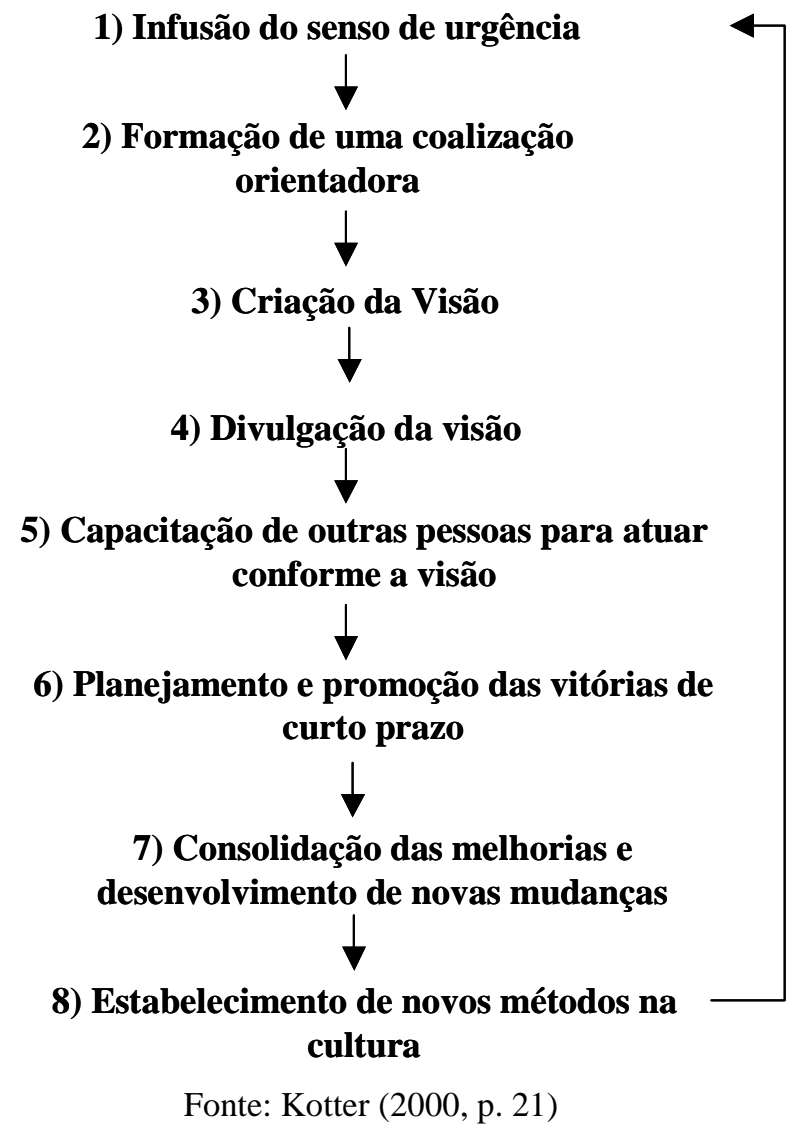

Nessa ilustração, as quatro primeiras etapas visam anular as forças da inércia, ou seja, descongelar o status quo. As fases subsequentes, de cinco a sete, visam à implementação do estado futuro e a última etapa objetiva estabelecer as mudanças na cultura corporativa, consolidando a implementação e também preparando a empresa para novas transformações.

Embora esses modelos sejam mais adequados a processos de transformações descontínuas, algumas fases são importantes para qualquer tipo de processo de mudança, quais sejam:

- criação do senso de urgência pertinente (ADIZES, 1995) (KOTTER, 1999, 2000, 2001) (HAYES, 2002) (BURNES, 2003): estabelecimento de um estado, através da evidência da crise, problema ou oportunidade, no qual a complacência deverá estar praticamente ausente.

- estabelecimento de uma coalizão administrativa: formação de um grupo com autoridade suficiente para liderar a mudança (KOTTER, 2000) (HAYES, 2002).

- alinhamento com a visão: estabelecimento de consistência entre o processo de mudança e a visão da empresa (ADIZES, 1995) (KIRKBRIDGE, 1998) (QUATRO; HOEKSTRA; GILLEY, 2002).

- capacitação de pessoas para atuarem conforme a visão: construção do empowerment do grupo através da eliminação de obstáculos ao processo de transformação e encorajamento para correr riscos (ADIZES, 1995) (HAYES, 2002) (QUATRO; HOEKSTRA; GILLEY, 2002).

- planejamento e promoção de conquistas de curto prazo: estabelecimento de metas a curto prazo para serem atingidas e comemoradas (ANDERSON; ANDERSON, 2001; QUATRO; HOEKSTRA; GILLEY, 2002), ou seja, a seleção de objetivos menores com soluções rápidas visando ao aumento da confiança dos funcionários (ADIZES, 1995). 
Todos os modelos apresentados até aqui reforçam a importância de três estágios fundamentais para qualquer processo de mudança e, consequentemente, essenciais à sua gestão:

- diagnóstico - promove o entendimento de onde a organização está (estado presente) e para onde ela deverá se mover (estado futuro);

- estratégias e planos - move a organização para o estado futuro;

- implementação - traduz as intenções em esforços de ação e gerencia as questões interpessoais associadas à mudança.

Kotter (2000) afirma que algumas empresas criam a ilusão de que a eliminação de fases podem aumentar a velocidade do processo de mudança, entretanto, ignorar alguma etapa do processo ou adiantar-se demais sem ter uma base sólida, pode produzir resultados insatisfatórios para a empresa.

Uma estratégia de gerenciamento da mudança, além da dimensão dos processos, deve necessariamente enfocar aspectos referentes às pessoas (ANDERSON; ANDERSON, 2001) (HAYES, 2002). Muitas estratégias de transformação falham drasticamente porque separam mudança organizacional e técnicas (conteúdo) das mudanças humanas e culturais (pessoas) (HUCZYNSKI; BUCHANAN, 1997).

\section{Questões referentes às relações interpessoais}

O processo de mudança se faz essencialmente por intermédio das pessoas. Elas conduzem, participam, implementam e são impactadas pelas mudanças. A gestão da mudança, para Duck (1999), significa gerenciar a integração entre as pessoas que lideram o programa da mudança e aquelas que devem implementar as novas estratégias, desenvolver um contexto organizacional propício à mudança e administrar as conexões emocionais essenciais em qualquer transformação, visando à satisfação de todos os envolvidos.

Senge (2001) argumenta que a maior parte dos insucessos na tentativa de mudar ocorre porque é comum haver um número muito pequeno de pessoas efetivamente comprometidas com a mudança. Para Belasco (1992) e Adizes (1995) as pessoas são a chave do processo, por isso a empresa deve se cercar dos melhores profissionais, ter uma política de gestão de pessoas que estimule a mudança e divulgar a visão para que todos tenham ciência do que a empresa espera dos seus funcionários. Na mesma linha, Kotter (1999) afirma ser fundamental a formação de uma poderosa coalizão de pessoas para liderar e motivar o esforço de mudança e complementa que uma grande mudança é impossível, a menos que a maioria dos funcionários a deseje. Assim, os funcionários de uma organização sempre foram e sempre serão o mais importante recurso no gerenciamento de mudança (SIMS; SIMS, 2002). Hayes (2002) afirma que o gerenciamento das questões interpessoais em um processo de mudança é essencial para a geração e manutenção da satisfação dos participantes.

Portanto, questões como comunicação, treinamento e desenvolvimento, motivação, interesses pessoais são aspectos inerentes a processos de transformação. Existem muitas questões interpessoais relacionadas aos processos de mudança, porém, dada a delimitação do escopo neste artigo, as questões interpessoais apresentadas a seguir são aquelas consideradas convergentes dentre a maioria dos autores levantados (KOTTER; SCHLESINGER, 1979) (ADIZES, 1995) (HUCZYNSKI; BUCHANAN, 1997) (STICKLAND, 1998) (DUCK, 1999) (KOTTER, 1999, 2000, 2001) (ANDERSON; ANDERSON, 2001) (HAYES, 2002) (SIMS; SIMS, 2002) (HOAG; RITSCHARD; COOPER, 2002) (BURNES, 2003).

\section{Comunicação}

A qualidade da comunicação pode ter um importante impacto nos programas de mudança. Durante todo o processo, os participantes requerem informações dos seus líderes, assim como estes requerem informações dos participantes, ou seja, a comunicação é constante (HAYES, 2002).

Segundo Burnes( 2003), para o projeto ter sucesso é necessário que os condutores do processo comuniquem constantemente a forma como as mudanças devem caminhar. Se as mensagens forem claras, serão entendidas e se forem concretizadas, terão credibilidade (ADIZES, 1995). Portanto, é esperado dos líderes comunicarem-se 
de forma clara, objetiva e simples e de também perceberem interpretarem e usarem as informações providas pelos participantes (STICKLAND, 1998).

Segundo Sims e Sims (2002), nos programas de transformação de maior êxito, os executivos recorrem a todos os canais de comunicação existentes para difundir a visão do processo e agem conforme o discurso. Convertem os informativos da empresa, quase sempre enfadonhos e raramente lidos, em arautos vibrantes da visão.

\section{Motivação}

Stickland (1998) define motivação como a prontidão das pessoas em persistir contra dificuldades e frustrações encontrando uma "força superior". Hayes (2002) afirma que, sob a perspectiva da teoria da expectativa (expectancy theory), o comportamento de resistência ou suporte à mudança é função de dois fatores: expectativas sobre o futuro e atratividade dos resultados. Segundo o autor, a expectativa ou crença sobre o relacionamento entre esforço, performance e resultado que agregue valor determina a motivação para apoiar ou resistir à mudança de um stakeholder.

Kotter e Schlesinger (1979) identificam algumas maneiras de motivar e lidar com a resistência à mudança. Algumas delas são corroboradas por outros autores, conforme segue:

- Educação e persuasão: educar as pessoas para a necessidade de mudar, utilizando métodos para aumentar a adesão a mudanças (ADIZES, 1995) (KIRKBRIDGE, 1998) (KOTTER, 1999, 2000, 2001) (ANDERSON; ANDERSON, 2001) (HAYES, 2002);

- Participação e envolvimento: excitar, motivar e ajudar a criar uma percepção compartilhada da necessidade de mudança com um grupo alvo (GRANVILLE, 1996) (ANDERSON; ANDERSON, 2001) (SIMS; SIMS, 2002);

- Facilitação e suporte: dar tempo e oportunidade às pessoas para desvincularem-se do estado presente (ADIZES, 1995) (HUCZYNSKI; BUCHANAN, 1997) (STICKLAND, 1998) (KOTTER, 1999, 2000, 2001) (SENGE, 2001, 2004) (HAYES, 2002) (HOAG; RITSCHARD; COOPER, 2002) (BURNES, 2003);

Negociação e acordo: recompensar os comportamentos que facilitem a mudança (ADIZES, 1995) (KOTTER, 1999 2000, 2001) (ANDERSON; ANDERSON, 2001) (HAYES, 2002) (SIMS; SIMS, 2002).

\section{Treinamento e desenvolvimento}

Mudanças organizacionais normalmente são associadas com mudanças dos indivíduos, porém, dependendo do tipo da mudança a ser realizada, é necessário realizar treinamentos específicos visando ao desenvolvimento de novos conhecimentos, habilidades, atitudes e comportamentos (KOTTER, 2000) (ANDERSON; ANDERSON, 2001) (SIMS; SIMS, 2002). Nesse sentido, o treinamento pode estar direcionado a dois tipos de pessoas: aquelas que necessitam desempenhar novos papéis associados ao gerenciamento da mudança e aquelas que, como um resultado da mudança, necessitam se comportar diferentemente, demandando treinamento para capacitá-las a atingirem os novos padrões de desempenho (HAYES, 2002).

Sims e Sims (2002) ressaltam a importância de as empresas treinarem seus funcionários para os conhecimentos e habilidades necessários para participarem efetivamente dos processos de decisão.

\section{Interesses Pessoais}

As pessoas possuem interesses pessoais diferentes e reagem de formas distintas a mudanças. Por isso, é importante considerar como as pessoas envolvidas poderão responder à mudança desejada e definir um plano de ação visando facilitar a sua adaptação (HAYES, 2002).

Diferenças de comportamentos e atitudes significam conflito em potencial, sendo assim, inevitável em qualquer processo (ADIZES, 1995) (KOTTER, 1999) (QUATRO; HOEKSTRA; GILLEY, 2002). O conflito é um subproduto da mudança e pode ser destrutivo ou construtivo (HAYES, 2002). Para ser construtivo, de acordo com Adizes (1995), deve existir respeito e confiança mútua entre os participantes da mudança. Segundo o 
autor, o respeito mútuo é essencial para que o aprendizado ocorra através das diferenças e a confiança mútua é necessária para que exista um clima favorável futuro. Assim, o conflito é construtivo e sinérgico quando pessoas diferentes entre si aprendem com suas diferenças e, isso é possível, através da comunicação e respeito mútuo.

Se houver a percepção por parte dos participantes de se obter um clima favorável a todos, pelo menos a longo prazo, e se houver a confiança, acreditando que os desequilíbrios de interesses a curto prazo possam ser compensados, os conflitos serão canalizados para se tornarem construtivos (KOTTER, 2000).

\section{O Recof como gerador da mudança}

O Recof é um regime fiscal especial instituído pela Secretaria da Receita Federal -SRF como forma de incentivar a exportação de mercadorias e proporcionar melhor aproveitamento dos benefícios inerentes ao comércio internacional. Esse regime foi criado em 1997, especialmente para a indústria de informática e telecomunicações, e posteriormente ampliado para os setores automobilístico, aeronáutico, e outros.

Objetiva especificamente agilizar o desembaraço aduaneiro de mercadorias importadas e exportadas e gerar reduções tributárias relacionadas às operações de comércio exterior. A utilização de tais vantagens está atrelada ao cumprimento de metas de exportação, à implementação de sistemas informatizados e à implementação de modificações nos processos organizacionais de compras, recebimento, importação, e outros, por parte das empresas usuárias.

Para efeitos desse artigo, o Recof não foi abordado pela sua dimensão de um incentivo fiscal, mas sim como um fator gerador de mudanças. A sua adoção requer das empresas um maior controle nas suas operações (SALES, 2004), envolvendo aspectos de comportamento (comprometimento dos envolvidos) e de processos em diversas áreas (PORTUGAL, 2005). Assim, para usufruir e manter as vantagens proporcionadas pelo regime, é preciso, antes, alterar a forma como a empresa executa, controla e operacionaliza seus processos (FRANCESCINI NETO, 2005), principalmente aqueles referentes ao controle aduaneiro de entrada, permanência e saída de mercadorias.

Dada a possibilidade de ocorrer inesperadamente auditoria por parte da fiscalização aduaneira, as empresas precisam certificar-se que estão agindo em conformidade com os procedimentos estabelecidos pelo Recof.

\section{Procedimentos metodológicos}

\section{Tipo e método da pesquisa}

Este artigo está fundamentado em uma pesquisa exploratória de natureza descritiva em que se utilizou o método qualitativo, uma vez que proporciona visão geral acerca de determinado fato sobre o qual não se tem maiores informações (GIL, 2002) (RICHARDSON, 1999).

\section{População e amostra}

As empresas de telecomunicações usuárias do Recof constituíram a população da pesquisa. Por se tratar de um ambiente muito amplo para a análise, uma vez que podem ser usuárias do Recof todas as empresas desse setor, houve a necessidade da seleção de uma amostra não probabilística, tendo em vista incluir aquelas que tivessem experiência relevante com a implantação desse incentivo. Para isso, buscou-se selecionar as maiores empresas fornecedoras de equipamentos de telecomunicações, representativas e destacadas neste setor, com base no ranking das 100 maiores empresas de telecomunicações do Anuário de Telecom (2005), resultando na escolha das empresas Motorola, Siemens e Ericsson. 


\section{Caracterização das empresas}

\section{Siemens}

Esta empresa está presente em mais de 190 países e é uma das líderes do mercado eletroeletrônico brasileiro ofertando uma gama variada de produtos, serviços e soluções de infraestrutura tecnológica para telecomunicações, indústria de base, energia elétrica, transporte metro-ferroviário, medicina e iluminação, redes móveis, etc. Instalada no Brasil em 1905, a Siemens conta com 10.305 colaboradores, seis centros de pesquisa e desenvolvimento e catorze unidades fabris. Voltada às exportações, a fábrica em Curitiba opera o Recof desde dezembro de 2003, com resultados positivos em relação às exportações. Seu crescimento se deve principalmente às exportações de centrais de comunicação corporativa fabricadas em Curitiba, onde $90 \%$ dos materiais importados são adquiridos com o benefício do regime Recof.

\section{Motorola Industrial}

A Motorola é uma empresa mundial americana fornecedora de produtos e soluções de mobilidade nas áreas de banda larga, sistemas integrados e redes sem fio. Instalada no Brasil em 1992, a empresa mantém 6.500 empregos diretos, distribuídos nos escritórios de vendas e no complexo industrial em Jaguariúna, no Estado de São Paulo, considerado também grande centro exportador. A empresa é hoje uma das maiores exportadoras de bens de tecnologia da informação do País, totalizando mais de US\$ 4 bilhões desde o início das suas operações. Como forma de incentivar e estimular suas exportações, o complexo industrial opera o Recof desde junho de 1999, sendo que aproximadamente 95\% dos seus materiais importados são adquiridos com beneficio desse incentivo.

\section{Ericsson Telecomunicações}

A Ericsson Telecomunicações é uma empresa multinacional sueca, presente em mais de 140 países. No Brasil desde 1924, atua na oferta de equipamentos, soluções e serviços de telecomunicações para todas as tecnologias de sistemas móveis e redes fixas presentes no mercado brasileiro. Emprega cerca de 1.900 funcionários, distribuídos na matriz em São Paulo, na área industrial em São José dos Campos, no Centro de Pesquisas e Desenvolvimento em Indaiatuba (o único da América Latina) e nos escritórios regionais espalhados pelo País. É reconhecida pela matriz norte-americana como polo de grande porte para a exportação de equipamentos para os mercados da América Latina e África. A Ericsson utiliza-se do Recof desde 2003.

\section{Sujeitos da pesquisa e coleta de dados}

Os sujeitos da pesquisa, que totalizaram oito entrevistados nas três empresas, foram: os gerentes do projeto de implementação do Recof, responsáveis pela gestão da mudança, e as pessoas-chave no projeto de implementação (key-user), aquelas que participaram ativamente da implementação das mudanças. Foi realizada pesquisa de campo (VERGARA, 2000) com a utilização de entrevistas em profundidade (AAKER;KUMAR;DAY., 2004) com um roteiro semiestruturado (VERGARA, 2002), com 31 perguntas abertas, divididas em seis blocos com objetivos específicos, elaboradas com base no referencial teórico do estudo, distribuídas em blocos conforme segue:

Bloco 1 - Dados do respondente: conhecer o perfil dos entrevistados.

Bloco 2 - Dados do projeto: obter informações administrativas sobre o processo de implantação do Recof (por exemplo: tempo de duração do projeto, tempo de utilização do benefício, etc).

Bloco 3 - Dados da empresa: conhecer o perfil da empresa.

Bloco 4 - Processo da mudança: identificar as fases do processo de mudança executadas durante o projeto de implantação. 
Bloco 5 - Relações interpessoais: esclarecer como as questões interpessoais foram tratadas durante o projeto.

Bloco 6 - Gestão da mudança: descobrir como a mudança foi gerida na empresa durante o projeto de implementação do Recof.

As entrevistas duraram, em média, uma hora e trinta minutos e foram gravadas com a devida permissão dos entrevistados, porém, sob a condição de não serem eles identificados por empresa quando da análise dos resultados. Posteriormente, todas as falas foram transcritas ipsis literis visando à análise e interpretação dos dados. Para a validação do roteiro como instrumento de coleta de dados foi realizado um pré-teste em uma empresa que não constituiu parte da amostra, (VERGARA, 2002) por meio de entrevista em profundidade in loco com o gerente do projeto de implementação das mudanças.

Em função do sigilo solicitado pelos entrevistados, na análise dos dados os nomes das empresas e dos respondentes foram substituídos pelas seguintes denominações:

- empresas: nomes substituídos por letras, iniciando pela letra "A", obedecendo à ordem das entrevistas;

- entrevistados: nomes substituídos pela letra "R" significando "respondente", seguidos por números ordinais atribuídos de acordo com a ordem das entrevistas, e pela letra correspondente à empresa.

Como participaram da pesquisa três representantes da empresa A e B e dois representantes da empresa C, a nomenclatura utilizada foi a seguinte:

- Empresa $A: R_{1} A, R_{2} A$ e $R_{3} A$;

- Empresa $B: R_{1} B, R_{2} B$ e $R_{3} B$;

- Empresa C: $\mathrm{R}_{1} \mathrm{C}$ e $\mathrm{R}_{2} \mathrm{C}$;

Dos oito respondentes, três eram gerentes do projeto (um de cada empresa) e cinco eram pessoas-chave na implementação dos projetos (dois da Empresa A, dois da Empresa B e um da Empresa C).

\section{Tratamento dos dados}

Os dados foram tratados por meio da análise de conteúdo (BARDIN, 2000) porque, segundo Flick (2004), é a mais apropriada para estudar material textual de tipo qualitativo, e está voltada a compreender um discurso, aprofundar suas características e extrair dele relatos importantes (RICHARDSON, 1999). Foram seguidos os três polos cronológicos de Bardin (2000):

1. pré-análise: transcrição ipsis literis das falas dos entrevistados e, em seguida, uma leitura flutuante, visando a um melhor entendimento das falas;

2. exploração das entrevistas em profundidades: recorte do texto em unidades comparáveis de categorização e de modalidade de codificação cujos critérios adotados estão descritos mais adiante;

3. tratamento dos resultados: interpretações dos resultados obtidos, visando responder aos objetivos do estudo. A unidade de codificação dos dados (RICHARDSON, 1999) concentrou-se na frase dos entrevistados e a categorização foi realizada por meio da análise temática com a utilização do critério semântico (tema), sendo este definido a priori (FLICK, 2004). As categorias e subcategorias construídas, a partir da análise temática e condensação dos temas presentes nas respostas dos entrevistados, estão apresentadas a seguir, guardando a conexão com os objetivos específicos deste artigo.

\section{Aspectos relevantes da gestão da mudança}

Considerando as opiniões dos entrevistados contidas nas respostas das questões do Bloco 4 (Processo da Mudança) e Bloco 6 (Gestão da Mudança), foram construídas as categorias que representaram, segundo o 
ponto de vista dos entrevistados, o que foi considerado efetivamente relevante na gestão da implementação da mudança:

- "planejamento das atividades": a gestão da mudança contemplou o planejamento das atividades, como por exemplo, cronograma, prazo, etc,.;

- "comprometimento": a gestão da mudança influenciou no comprometimento e engajamento dos participantes;

- "cultura para a mudança": foram reforçados os benefícios da realização de mudanças e da implementação de inovações de processos;

- "envolvimento": o envolvimento das pessoas-chave que tinham a expertise dos processos;

- "suporte": a presença do alto escalão no projeto e seu suporte foi importante para garantir a condução das atividades;

- "existência de método": a gestão da mudança feita em fases e que o tratamento das questões interpessoais facilitou o atingimento dos objetivos.

O Quadro 1 apresenta a maneira como foram construídas essas categorias, com base nas falas mais significativas dos entrevistados, na ordem da realização das entrevistas. 


\section{Quadro 1 - Categorização dos aspectos relevantes da gestão da mudança}

\begin{tabular}{cl}
\hline CATEGORIA & \multicolumn{1}{c}{ EMPRESA A } \\
\hline & $\begin{array}{l}\mathrm{R}_{1} \mathrm{~A}:[\ldots] \text { a existência de um } \\
\text { grupo de programa..., com } \\
\text { atividades e prazos definidos } \\
\text { foi muito importante. }\end{array}$ \\
& $\mathrm{R}_{2} \mathrm{~A}:[. .$.$] ter um cronograma$ \\
com todas as \\
Planejamento das \\
atividades & esponsabilidades \\
& de acompanhamento.
\end{tabular}

\section{$\mathrm{R}_{1} \mathrm{~A}:[\ldots] \mathrm{O}$}

comprometimento das pessoas foi muito bom. A cooperatividade, dedicação, quando necessária, foi de $100 \%$.

$\mathrm{R}_{2} \mathrm{~A}:[\ldots]$ um alto de grau de Comprometimento comprometimento. De fato vestiram a camisa.

$\mathrm{R}_{3} \mathrm{~A}$ : [...] Foi um projeto que deu certo, porque a gente foi a fundo mesmo.

TEMA

EMPRESA B

EMPRESA C

$\mathrm{R}_{1} \mathrm{~B}$ : [...] O fato de termos as atividades planejadas teve muita influência também no atingimento dos objetivos. $\mathrm{R}_{2} \mathrm{~B}:[. .$.$] prazos, metas,$ objetivos, o que tem que fazer, isso era claro e auxiliou no atingimento dos objetivos. $\mathrm{R}_{3} \mathrm{~B}:[\ldots]$ tem todos os passos do projeto, o quê (que) tem que ser levado em consideração, ou seja, se tem algum gap ou não. $\mathrm{R}_{1} \mathrm{~B}:[\ldots]$ eu achei primordial, se não houvesse engajamento a gente não teria conseguido. R2B: [...] as pessoas também estavam comprometidas e os motivos que fizeram com que as pessoas estivessem engajadas foi a informação.
$\mathrm{R}_{1} \mathrm{C}$ : [...] Com certeza o cronograma auxiliou no atingimento dos objetivos através do acompanhamento e planejamento das atividades. Ele existia de fato e era muito utilizado e consultado, não foi algo que a gente construiu e esqueceu.
$\mathrm{R}_{1} \mathrm{C}:[. .$.$] por mais difícil que$ pareça, se todo mundo estiver engajado, imbuído na mesma causa, a coisa acontece.

$\mathrm{R}_{2} \mathrm{C}$ : [...] estava todo mundo engajado para fazer a coisa acontecer, acho que isso foi fundamental.
$\mathrm{R}_{1} \mathrm{~A}:[\ldots]$ a experiência adquirida em projetos de mudança de processo, ou

Cultura para mudança

seja, a expertise desenvolvida para a gestão da mudança.

$\mathrm{R}_{2} \mathrm{~A}$ : [...] preocupação com a correção nos processos [...].

$\mathrm{R}_{1} \mathrm{~A}$ : [...] envolvimento das pessoas com a expertise no processo - das pessoas-chave para o correto mapeamento dos processos e hand-over das atividades e conhecimento relacionadas aos processos para o grupo. $\mathrm{R}_{2} \mathrm{~A}$ : [...] O que eu achei positivo foi a colocação de pessoas [...]dedicadas exclusivamente ao projeto. $\mathrm{R}_{3} \mathrm{~A}$ : [...] foi melhorado o processo com o envolvimento das pessoas [...] Foi um projeto que envolveu todo mundo.
$\mathrm{R}_{1} \mathrm{~B}:[\ldots]$ a gente tinha que contar com todas as áreas para que nos mostrassem os processos deles, para definir os novos e alinhar o entendimento. $\mathrm{R}_{2} \mathrm{~B}$ : [...] Envolver bem a parte da diretoria, ou seja, o sponsor, e também o pessoal de base. Você tem que ter apoio do alto escalão, por outro lado você tem que trabalhar muito bem nas bases para que você tenha o pessoal de conhecimento o apoiando.

$\mathrm{R}_{3} \mathrm{~B}:[\ldots]$ o envolvimento das pessoas-chave das áreas que entenderam a necessidade do Recof para a empresa [...].
$\mathrm{R}_{1} \mathrm{C}:[\ldots]$ qualquer mudança de processo tem impacto no Recof, então o departamento Recof tem de ser questionado.

\section{$\mathrm{R}_{1} \mathrm{C}$ : [...] Para cada área de negócio foi definido um focal point e essa pessoa deveria ter no mínimo um nível de supervisão para acompanhar as reuniões, entender quais eram as novas necessidades do Recof e implementar isso.}




\begin{tabular}{|c|c|c|c|}
\hline Suporte & $\begin{array}{l}\mathrm{R}_{1} \mathrm{~A}:[\ldots] \text { sensibilização da } \\
\text { Diretoria e } \\
\text { consequentemente apoio na } \\
\text { implementação. } \\
\mathrm{R}^{2} \mathrm{~A}:[\ldots] \text { A direção da } \\
\text { empresa nos delegou [...]e } \\
\text { nos deu a responsabilidade e } \\
\text { autoridade para tocar. } \\
\mathrm{R} 3 \mathrm{~A}:[\ldots] \text { envolvimento dos } \\
\text { superiores diretos e indiretos } \\
\text { porque, sem o envolvimento } \\
\text { deles, não teria acontecido } \\
\text { no momento que aconteceu. } \\
{[\ldots]}\end{array}$ & $\begin{array}{l}\mathrm{R}_{2} \mathrm{~B}:[\ldots] \text { tinha alguém que lhe } \\
\text { desse esse respaldo, que } \\
\text { assinasse, que garantisse, que o } \\
\text { apoiasse naquilo. } \\
\mathrm{R}_{3} \mathrm{~B}:[\ldots] \text { se tinha algum } \\
\text { showstopper, eles sempre } \\
\text { corriam atrás para estar } \\
\text { resolvendo para que não } \\
\text { impactasse o projeto. [...] o } \\
\text { corpo diretivo e gerência } \\
\text { estavam realmente engajados no } \\
\text { projeto e estavam contribuindo } \\
\text { para que as coisas acontecessem } \\
\text { da melhor forma possível. }\end{array}$ & $\begin{array}{l}\mathrm{R}_{1} \mathrm{C}:[\ldots] \text { A metodologia } \\
\text { utilizada pelos gerentes de } \\
\text { estarem sempre próximos e } \\
\text { envolvidos no projeto } \\
\text { contribuiu bastante [...]. } \\
\mathrm{R}_{2} \mathrm{C}:[\ldots] \text { eu acho que o } \\
\text { envolvimento começou daí. } \\
\text { Todos os gerentes da } \\
\text { empresa estavam cientes do } \\
\text { quanto isso era importante } \\
\text { para a gente. A diferença } \\
\text { que isso iria significar no } \\
\text { nosso dia-a-dia. }\end{array}$ \\
\hline $\begin{array}{l}\text { Existência de } \\
\text { Método }\end{array}$ & $\begin{array}{l}\mathrm{R}_{1} \mathrm{~A} \text { : tudo isso, todas essas } \\
\text { atividades oriundas e } \\
\text { previstas no método foram } \\
\text { fundamentais para o } \\
\text { atingimento dos objetivos. } \\
\mathrm{R}_{2} \mathrm{~A} \text { : [...] a forma como a } \\
\text { gente organizou o projeto. } \\
\text { Não entregamos o projeto } \\
\text { para uma estrutura de } \\
\text { projeto, o projeto era de } \\
\text { todos. O gerenciamento no } \\
\text { sentido de envolver e } \\
\text { comprometer cada um } \\
\text { dentro de cada etapa. }\end{array}$ & $\begin{array}{l}\mathrm{R}_{1} \mathrm{~B}:[\ldots] \text { uma estrutura de } \\
\text { implementação de projeto muito } \\
\text { bem acompanhada porque, se } \\
\text { não tivesse isso, também a gente } \\
\text { não teria conseguido. Me refiro } \\
\text { ao método [...] quando você tem } \\
\text { um método, você segue aquele } \\
\text { caminho e ele exige que você } \\
\text { não corte processos, steps, que } \\
\text { depois irão fazer falta mais para } \\
\text { frente. } \\
\mathrm{R}_{2} \mathrm{~B}:[\ldots] \text { o método fez com que } \\
\text { enxergasse o início, meio e fim } \\
\text { do projeto. [...] aonde eu quero } \\
\text { chegar, aonde eu vou..[...] o } \\
\text { método está diretamente } \\
\text { relacionado com o atingimento } \\
\text { dos objetivos. } \\
\mathrm{R}_{3} \mathrm{~B}:[\ldots] \text { é claro para todo } \\
\text { mundo o que tem que ser feito e } \\
\text { todo mundo segue [...]todo } \\
\text { mundo conhece o status do } \\
\text { projeto, onde o projeto está, e } \\
\text { qual a sua atividade dentro do } \\
\text { projeto. }\end{array}$ & \\
\hline
\end{tabular}

Fonte: Elaborado pelos autores

\section{Fases do processo de mudança}

Para a coleta e análise do processo de mudança tomou-se como referência os modelos de Hayes (2002, p. 54) representado na Figura 1, referente à sua visão sobre os passos envolvidos no processo de mudança, e de Kotter (2000, p. 21) representado na Figura 2, referente às oito etapas da criação de uma grande mudança.

Por meio da análise das respostas às questões dos Blocos 4 (Processo da Mudança) e 6 (Gestão da Mudança), foram construídas cinco categorias que representaram e caracterizaram as fases do processo de mudança (HAYES, 2002) executadas pelas três empresas:

- "identificação da necessidade de mudança" ( $1^{\mathrm{a}}$ fase): o fato gerador da implementação dos projetos, desdobrada nas subcategorias "redução de custo", "mercado externo" e "ganho financeiro";

- "início do processo de mudança" ( $2^{\mathrm{a}}$ fase): as atividades realizadas que deram início à implementação dos projetos, a partir das quais foram criadas as subcategorias "entendimento da legislação", "elaboração de business case", "identificação das pessoas" e "kickoff";

- "diagnóstico" ( $3^{a}$ fase): visão da situação futura que, segundo eles, não era clara, desdobrada na subcategoria "visão incerta"; 
- "planejamento e preparação" (4a fase): composta pelas subcategorias "elaboração de cronograma" e "elaboração de organograma", sobre as atividades de planejamento e preparação para mudanças executadas pelas empresas;

- "implementação" ( $5^{\mathrm{a}}$ fase): desdobrada nas subcategorias "mapeamento de processo", "implementação das ações" planejadas no cronograma e "desenvolvimento de sistema".

O Quadro 2 ilustra a maneira como foram construídas essas categorias e subcategorias, com base nas falas mais relevantes, por ordem das entrevistas.

Quadro 2- Categorização das fases do processo de mudança

\begin{tabular}{|c|c|c|c|c|}
\hline & & \multicolumn{3}{|c|}{ TEMA } \\
\hline CATEGORIA & $\begin{array}{c}\text { SUB- } \\
\text { CATEGORIA } \\
\end{array}$ & EMPRESA A & EMPRESA B & EMPRESA C \\
\hline \multirow{3}{*}{$\begin{array}{l}\text { Identificação } \\
\text { Necessidade de } \\
\text { Mudança } \\
\left(1^{\mathrm{a}} \text { fase }\right)\end{array}$} & Redução de Custo & $\begin{array}{l}\mathrm{R}_{1} \mathrm{~A}:[\ldots] \text { precisava ter } \\
\text { custos menores e ser mais } \\
\text { competitiva [...] para } \\
\text { trazer uma linha de } \\
\text { produção para o Brasil } \\
\mathrm{R}_{3} \mathrm{~A}:[\ldots] \text { para trazer uma } \\
\text { linha de produção para a } \\
\text { fábrica }[\ldots]\end{array}$ & $\begin{array}{l}\mathrm{R}_{1} \mathrm{~B}:[\ldots] \text { redução de } \\
\text { custo e novas } \\
\text { oportunidades de } \\
\text { negócios, de aumento } \\
\text { da exportação. } \\
\mathrm{R}_{3} \mathrm{~B} \text { : [...] necessidade } \\
\text { de reduzir custos e } \\
\text { tornar a empresa mais } \\
\text { competitiva. }\end{array}$ & \\
\hline & Mercado Externo & $\begin{array}{l}\mathrm{R}_{2} \mathrm{~A}:[\ldots] \text { planejamento } \\
\text { estratégico previa } \\
\text { aumento de exportação. }\end{array}$ & $\begin{array}{l}\mathrm{R}_{2} \mathrm{~B}:[\ldots] \text { tínhamos a } \\
\text { necessidade de estar } \\
\text { ganhando o mercado } \\
\text { externo. }\end{array}$ & \\
\hline & Ganho Financeiro & & & $\begin{array}{l}\mathrm{R}_{1} \mathrm{C}:[\ldots] \text { pelo ganho } \\
\text { financeiro. } \\
\mathrm{R}_{2} \mathrm{C}:[\ldots] \text { porque } \\
\text { existe ganho no } \\
\text { tempo de liberação da } \\
\text { mercadoria, ganho de } \\
\text { cashflow e tal. }\end{array}$ \\
\hline \multirow[t]{3}{*}{$\begin{array}{l}\text { Início do Processo } \\
\text { de Mudança } \\
\text { (2a fase })\end{array}$} & $\begin{array}{l}\text { Entendimento da } \\
\text { Legislação }\end{array}$ & $\begin{array}{l}\mathrm{R}_{2} \mathrm{~A}:[\ldots] \text { primeiro } \\
\text { procuramos nos informar } \\
{[\ldots . .]} \\
\mathrm{R}_{3} \mathrm{~A}:[\ldots] \text { procuramos } \\
\text { entender a legislação[...]. }\end{array}$ & $\begin{array}{l}\mathrm{R}_{1} \mathrm{~B}:[\ldots] \text { o } \\
\text { entendimento da } \\
\text { legislação e como isso } \\
\text { impacta nos processos } \\
\text { existentes na época. } \\
\mathrm{R}_{2} \mathrm{~B}:[\ldots] \text { Estudando o } \\
\text { processo Recof. }\end{array}$ & $\begin{array}{l}\mathrm{R}_{1} \mathrm{C}:[\ldots] \text { o início foi } \\
\text { bem a análise da } \\
\text { legislação, tentar } \\
\text { entender um } \\
\text { pouquinho que } \\
\text { "bicho" era esse [...]. }\end{array}$ \\
\hline & $\begin{array}{l}\text { Elaboração de } \\
\text { Business Case }\end{array}$ & $\begin{array}{l}\mathrm{R}_{1} \mathrm{~A}:[\ldots] \text { Mostramos os } \\
\text { benefícios internos da } \\
\text { implementação e também } \\
\text { os desafios. }\end{array}$ & $\begin{array}{l}\mathrm{R}_{1} \mathrm{~B}:[\ldots] \text { venda da ideia } \\
\text { para o alto escalão, } \\
\text { baseado em business } \\
\text { case. } \\
\mathrm{R}_{2} \mathrm{~B}:[\ldots] \text { tinha a parte } \\
\text { de } \text { business case. } \\
\mathrm{R}_{3} \mathrm{~B}:[\ldots] \text { Provar que o } \\
\text { Recof realmente é um } \\
\text { benefício e que trás } \\
\text { bons resultados. }\end{array}$ & $\begin{array}{l}\mathrm{R}_{1} \mathrm{C}:[\ldots] \text { aí foi feito } \\
\text { um business case } \\
\text { baseado nos dados de } \\
\text { que a gente dispunha } \\
\text { na época. }\end{array}$ \\
\hline & $\begin{array}{l}\text { Identificação das } \\
\text { pessoas }\end{array}$ & $\begin{array}{l}\mathrm{R}_{1} \mathrm{~A}:[\ldots] \text { Também foram } \\
\text { designadas as pessoas } \\
\text { para participar do projeto } \\
{[\ldots] .} \\
\mathrm{R}_{2} \mathrm{~A}:[\ldots] \text { Estruturamos } \\
\text { uma equipe }[\ldots] \text { e, a partir }\end{array}$ & $\begin{array}{l}\mathrm{R}_{1} \mathrm{~B}:[\ldots] \text { identificou } \\
\text { quais eram as áreas e as } \\
\text { pessoas com mais } \\
\text { senhoridade naquele } \\
\text { processo }[\ldots] \text {. } \\
\mathrm{R}_{2} \mathrm{~B}:[\ldots] \text { pessoas pelo }\end{array}$ & $\begin{array}{l}\mathrm{R}_{1} \mathrm{C}:[\ldots] \text { definiram } \\
\text { os focal points } \\
\text { responsáveis por } \\
\text { implementar as } \\
\text { mudanças. }\end{array}$ \\
\hline
\end{tabular}




\begin{tabular}{|c|c|c|c|c|}
\hline & & $\begin{array}{l}\text { daí, começamos a } \\
\text { especificar a necessidade } \\
\text { de implementações } \\
\mathrm{R}_{3} \mathrm{~A}:[\ldots] \text { quais eram as } \\
\text { tarefas, quais eram as } \\
\text { coisas a atacar [...] e a } \\
\text { partir desse start up } \\
\text { foram gerados vários } \\
\text { líderes. }\end{array}$ & $\begin{array}{l}\text { nível hierárquico }[\ldots] \text { e } \\
\text { pelo conhecimento do } \\
\text { processo. Os owners de } \\
\text { cada processo }[\ldots] . \\
\mathrm{R}_{3} \mathrm{~B}:[\ldots] \text { foram } \\
\text { levantadas as pessoas- } \\
\text { chave de algumas áreas } \\
{[\ldots] .}\end{array}$ & \\
\hline & KickOff & $\begin{array}{l}\mathrm{R}_{1} \mathrm{~A}:[\ldots] \text { foi feito um } \\
\text { kick-off com todos os } \\
\text { participantes. } \\
\mathrm{R}_{2} \mathrm{~A}:[\ldots] \text { foi feito um } \\
\text { kick-off. } \\
\mathrm{R}_{3} \mathrm{~A}:[\ldots] \text { foi o kick off } \\
\text { primeiro [...]. }\end{array}$ & $\begin{array}{l}\mathrm{R}_{2} \mathrm{~B}:[\ldots] \text { foi feito um } \\
\text { kick-off [...] você } \\
\text { mostra o business case, } \\
\text { você mostra como vai } \\
\text { ser desenvolvido o } \\
\text { projeto e pelo menos } \\
\text { um cronograma básico. }\end{array}$ & $\begin{array}{l}\mathrm{R}_{1} \mathrm{C}:[\ldots] \text { Teve o kick } \\
\text { off onde foram } \\
\text { mostrados os ganhos } \\
\text { financeiros, uma } \\
\text { ideia bem macro de } \\
\text { cronograma e o } \\
\text { ganho logístico. }\end{array}$ \\
\hline $\begin{array}{l}\text { Diagnóstico } \\
\left.\text { ( } 3^{\mathrm{a}} \text { fase }\right)\end{array}$ & Visão Incerta & $\begin{array}{l}\mathrm{R}_{1} \mathrm{~A}:[\ldots] \text { a visão } \\
\text { detalhada do que seria } \\
\text { mudado foi sendo } \\
\text { descoberta durante a } \\
\text { implementação. } \\
\mathrm{R}_{2} \mathrm{~A}:[\ldots] \text { A situação } \\
\text { futura não era clara }[. . .] \\
\text { foi se mostrando durante } \\
\text { o projeto. } \\
\mathrm{R}_{3} \mathrm{~A}:[\ldots] \text { a situação } \\
\text { futura foi sendo } \\
\text { descoberta aos poucos } \\
\text { durante o projeto. }\end{array}$ & $\begin{array}{l}\mathrm{R}_{1} \mathrm{~B}:[\ldots] \text { descobrimos } \\
\text { outros impactos quando } \\
\text { da implementação. } \\
\mathrm{R}_{2} \mathrm{~B}:[\ldots] \text { nós sabíamos } \\
\text { que tínhamos muitos } \\
\text { desafios em relação a } \\
\text { essa mudança, mas ela } \\
\text { não estava clara para a } \\
\text { gente. } \\
\mathrm{R}_{3} \mathrm{~B}:[\ldots] \text {, o dia-a-dia } \\
\text { do Recof foi sendo } \\
\text { descoberto aos poucos. }\end{array}$ & $\begin{array}{l}\mathrm{R}_{1} \mathrm{C}:[\ldots] \text { à medida } \\
\text { que a gente foi } \\
\text { desenvolvendo o } \\
\text { desenho do sistema, } \\
\text { foi sentindo mais as } \\
\text { necessidades de } \\
\text { mudanças dos } \\
\text { processos. } \\
\mathrm{R}_{2} \mathrm{C}:[\ldots . .] \text { ninguém } \\
\text { conhecia o Recof a } \\
\text { ponto de dizer o que } \\
\text { significava essa } \\
\text { mudança. }\end{array}$ \\
\hline \multirow[t]{2}{*}{$\begin{array}{l}\text { Planejamento e } \\
\text { preparação } \\
\left(4^{\mathrm{a}} \text { fase }\right)\end{array}$} & $\begin{array}{l}\text { Elaboração de } \\
\text { Cronograma }\end{array}$ & $\begin{array}{l}\mathrm{R}_{1} \mathrm{~A}:[\ldots] \text { existia um } \\
\text { cronograma desde o } \\
\text { início. } \\
\mathrm{R}_{2} \mathrm{~A}:[\ldots] \text { Existia um } \\
\text { cronograma proposto e } \\
\text { conduzido [...]. } \\
\mathrm{R}_{3} \mathrm{~A}:[\ldots] \text { Elaboração de } \\
\text { um cronograma com } \\
\text { todas as atividades e } \\
\text { responsáveis planejados }\end{array}$ & $\begin{array}{l}\mathrm{R}_{1} \mathrm{~B}:[\ldots] \text { Eram feitas } \\
\text { reuniões no começo, } \\
\text { quase que diárias, para } \\
\text { definir qual era o plano } \\
\text { de implementação e } \\
\text { quem era responsável } \\
\text { por sua devida } \\
\text { atividade. [...] } \\
\mathrm{R}_{2} \mathrm{~B}:[\ldots] \text { o cronograma } \\
\text { do projeto, que nós } \\
\text { dividimos em fases. } \\
\mathrm{R}_{3} \mathrm{~B}:[\ldots][\ldots] \\
\text { cronograma com } \\
\text { atividades específicas, } \\
\text { responsável e datas. }\end{array}$ & $\begin{array}{l}\mathrm{R}_{1} \mathrm{C}:[\ldots] \text { foi feito um } \\
\text { cronograma da } \\
\text { implementação [...]. } \\
\mathrm{R}_{2} \mathrm{C}:[\ldots] \text { Acho que a } \\
\text { gente conseguiu } \\
\text { endereçar bem isso } \\
\text { daí e colocar ações } \\
\text { que eram necessárias } \\
\text { para a operação estar } \\
\text { adaptada. [...] } \\
\text { tínhamos um } \\
\text { cronograma formal. }\end{array}$ \\
\hline & $\begin{array}{l}\text { Elaboração de } \\
\text { Organograma }\end{array}$ & & $\begin{array}{l}\mathrm{R}_{2} \mathrm{~B}:[\ldots] \text { estruturar o } \\
\text { projeto, para fazer o } \\
\text { organograma }[\ldots]\end{array}$ & $\begin{array}{l}\mathrm{R}_{1} \mathrm{C}:[\ldots] \text { tinha uma } \\
\text { organograma que era } \\
\text { em um nível bem } \\
\text { alto. }\end{array}$ \\
\hline $\begin{array}{l}\text { Implementação } \\
\left(5^{\mathrm{a}} \text { fase }\right)\end{array}$ & $\begin{array}{l}\text { Mapeamento de } \\
\text { Processo }\end{array}$ & $\begin{array}{l}\mathrm{R}_{1} \mathrm{~A}:[\ldots] \text { eram } \\
\text { identificados os impactos } \\
\text { e alterações nos processos } \\
\text { correntes. } \\
\mathrm{R}_{2} \mathrm{~A}:[\ldots] \text { fizemos }[\ldots] \\
\text { uma série de workshops } \\
\text { internos mostrando o que } \\
\text { era o Recof, qual era o } \\
\text { impacto }[\ldots] \\
\mathrm{R}_{3} \mathrm{~A}:[\ldots] \text { depois }\end{array}$ & $\begin{array}{l}\mathrm{R}_{1} \mathrm{~B}:[\ldots] \text { Aconteceram } \\
\text { workshops diversos. } \\
\text { [...] o objetivo era } \\
\text { alinhamento dos } \\
\text { processos existentes e } \\
\text { novos processos }[\ldots] . \\
\mathrm{R}_{2} \mathrm{~B}:[\ldots] \text { a gente } \\
\text { mostrou o que iria } \\
\text { mudar. } \\
\mathrm{R}_{3} \mathrm{~B}:[\ldots] \text { mapeados os }\end{array}$ & $\begin{array}{l}\mathrm{R}_{1} \mathrm{C}:[\ldots] \text { a gente } \\
\text { montava um desenho } \\
\text { do processo AS IS e } \\
\text { o processo futuro } \\
\text { como teria que ser } \\
\text { para atender o Recof. } \\
{[\ldots] \text { mapeamos os }} \\
\text { processos de todas as } \\
\text { áreas. Inclusive a } \\
\text { gente refez os }\end{array}$ \\
\hline
\end{tabular}




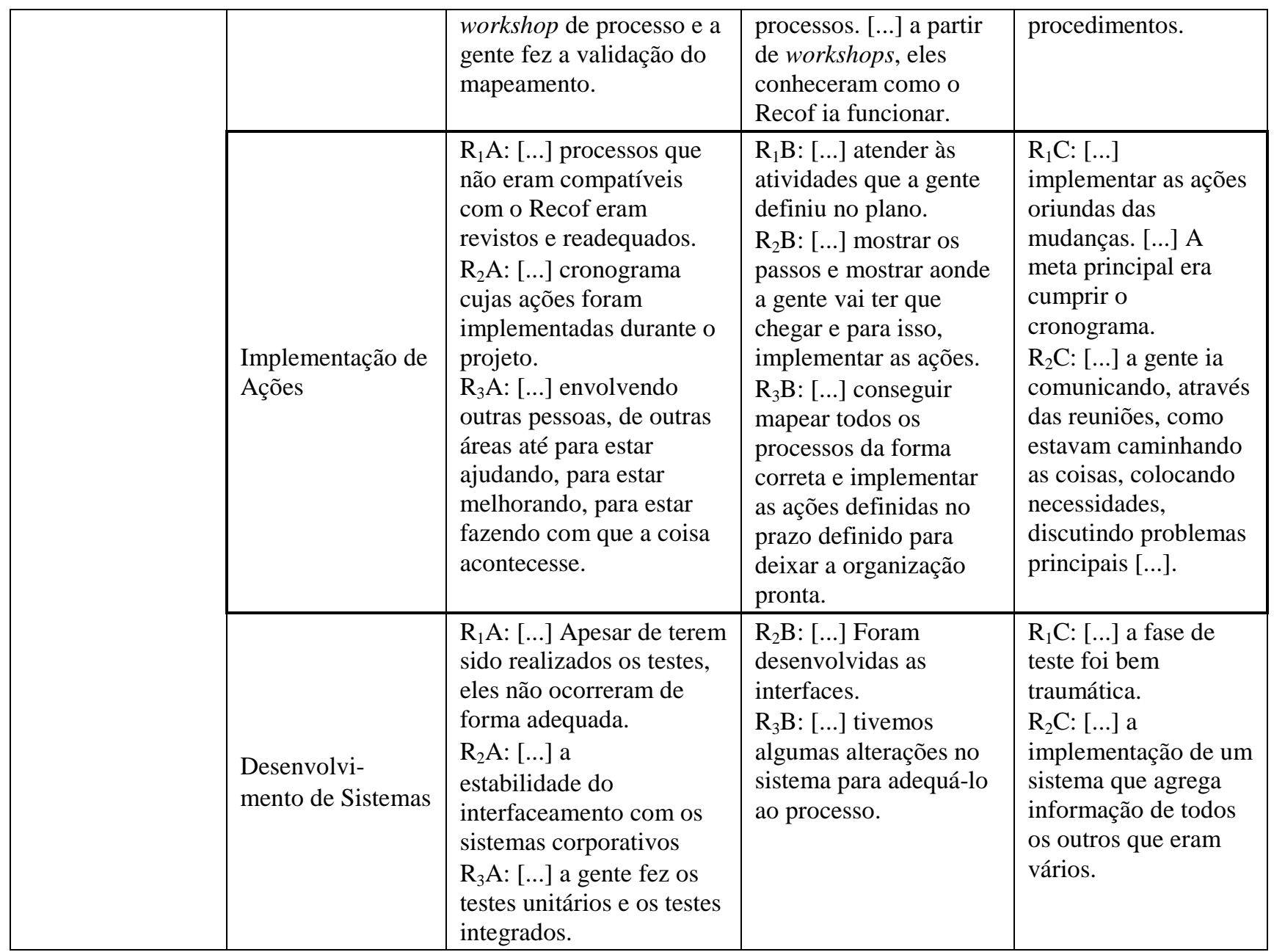

Fonte: Elaborado pelos autores

Alguns aspectos adicionais que surgiram espontaneamente nas entrevistas referentes às fases do processo de mudança, ressaltados no Referencial Teórico, mas que não se tornaram perguntas específicas, foram consolidados nas seguintes categorias:

- "criação senso de urgência": desdobrada nas subcategorias "segurança do emprego" e "ganho", caracterizaram como foi estabelecida a urgência para a mudança (KOTTER, 2001);

- "coalizão administrativa”: formação efetiva de um grupo com autoridade suficiente para gerar a mudança (HAYES, 2002), desdobrada na subcategoria "autoridade";

- "promoção de vitórias": sobre a falta de comemorações de vitórias quando do atigimento de metas intermediárias (ANDERSON; ANDERSON, 2001).

O Quadro 3 ilustra a elaboração das categorias e sub-categorias dessas descobertas adicionais. 
Quadro 3 - Categorização dos aspectos adicionais às fases do processo de mudança

\begin{tabular}{|c|c|c|c|c|}
\hline \multirow[b]{2}{*}{ CATEGORIA } & \multirow[b]{2}{*}{$\begin{array}{c}\text { SUB- } \\
\text { CATEGORIA }\end{array}$} & \multicolumn{3}{|c|}{ TEMA } \\
\hline & & EMPRESA A & EMPRESA B & EMPRESA C \\
\hline \multirow[t]{2}{*}{$\begin{array}{l}\text { Criação do Senso } \\
\text { de Urgência }\end{array}$} & $\begin{array}{l}\text { Segurança do } \\
\text { Emprego }\end{array}$ & $\begin{array}{l}\mathrm{R}_{1} \mathrm{~A}[\ldots] \text { se não } \\
\text { tivéssemos o Recof, a } \\
\text { existência da operação } \\
\text { fabril [...] estaria em } \\
\text { risco. [...] esse se } \\
\text { tornou um projeto de } \\
\text { vida ou morte para a } \\
\text { empresa. } \\
\mathrm{R}_{3} \mathrm{~A}:[\ldots] \text { o que ajudou } \\
\text { realmente foi [...] } \\
\text { falarem: "ó pessoal, ou } \\
\text { vocês fazem, ou } \\
\text { amanhã vocês estão na } \\
\text { rua". }\end{array}$ & $\begin{array}{l}\mathrm{R}_{1} \mathrm{~B}:[\ldots] \text { mostrar que } \\
\text { era uma oportunidade } \\
\text { de novo business para a } \\
\text { empresa [...] e, com } \\
\text { isso, vinha também a } \\
\text { segurança do emprego } \\
\mathrm{R}_{2} \mathrm{~B} \text { : [...] era uma } \\
\text { necessidade, era uma } \\
\text { sobrevivência. }\end{array}$ & \\
\hline & Ganhos & $\begin{array}{l}\mathrm{R}_{2} \mathrm{~A}:[\ldots] \text { era a única } \\
\text { alternativa que nós } \\
\text { tínhamos para nos } \\
\text { tornamos exportadores } \\
\text { para valer. }\end{array}$ & & $\begin{array}{l}\mathrm{R}_{1} \mathrm{C}:[\ldots] \text { é que tem um } \\
\text { ganho logístico e } \\
\text { financeiro muito } \\
\text { grande. } \\
\mathrm{R}_{2} \mathrm{C}:[. . .] \text { ia ajudar a } \\
\text { agilizar nossa operação. }\end{array}$ \\
\hline $\begin{array}{l}\text { Coalizão } \\
\text { Administrativa }\end{array}$ & Autoridade & $\begin{array}{l}\mathrm{R}_{1} \mathrm{~A}:[\ldots] \text { as pessoas } \\
\text { tinham autoridade para } \\
\text { tomar decisões. } \\
\mathrm{R}_{2} \mathrm{~A}:[\ldots] \text { nos deu a } \\
\text { responsabilidade e } \\
\text { autoridade para tocar. } \\
\mathrm{R}_{3} \mathrm{~A}:[\ldots] \text { tinha uma } \\
\text { voz que é isso e pronto, } \\
\text { tanto para o bem como } \\
\text { para o mal. }\end{array}$ & $\begin{array}{l}\mathrm{R}_{2} \mathrm{~B}:[\ldots] \text { Se a gente } \\
\text { precisasse parar o } \\
\text { projeto para tomar uma } \\
\text { decisão, como } \\
\text { aconteceu, a gente teria } \\
\text { esse respaldo. } \\
\mathrm{R}_{3} \mathrm{~B} \text { : [...] quem } \\
\text { participava no projeto } \\
\text { da área fiscal tinha toda } \\
\text { a autonomia em uma } \\
\text { decisão sobre algum } \\
\text { ponto do projeto. }\end{array}$ & $\begin{array}{l}\mathrm{R}_{1} \mathrm{C}:[\ldots] \text { quando dava } \\
\text { algum conflito em } \\
\text { alguma área [...] a } \\
\text { gerência intermediária } \\
\text { conseguia fazer a coisa } \\
\text { acontecer. } \\
\mathrm{R}_{2} \mathrm{C}:[\ldots] \text { estava sempre } \\
\text { com o meu gerente que } \\
\text { era o controller e } \\
\text { existia também na } \\
\text { equipe a gerente de IT. }\end{array}$ \\
\hline $\begin{array}{l}\text { Promoção de } \\
\text { Vitórias }\end{array}$ & & $\begin{array}{l}\mathrm{R}_{1} \mathrm{~A}:[\ldots] \text { não } \\
\text { ocorreram } \\
\text { comemorações durante } \\
\text { o projeto. } \\
\mathrm{R}_{2} \mathrm{~A}:[\ldots] \text { só no final da } \\
\text { implementação. } \\
\mathrm{R}_{3} \mathrm{~A}:[\ldots] \\
\text { Comemoração final. }\end{array}$ & $\begin{array}{l}\mathrm{R}_{1} \mathrm{~B}:[\ldots] \text { a gente não } \\
\text { comemorou muito. } \\
\mathrm{R}_{2} \mathrm{~B}:[\ldots] \text { pela nossa } \\
\text { correria, a gente nem } \\
\text { conseguiu fazer isso. } \\
\text { No final do projeto, a } \\
\text { gente comemorou. } \\
\mathrm{R}_{3} \mathrm{~B}:[\ldots] \text { cada etapa } \\
\text { que você cumpre é uma } \\
\text { comemoração mesmo } \\
\text { que informal. }\end{array}$ & $\begin{array}{l}\mathrm{R}_{1} \mathrm{C}:[\ldots] \text { foi uma } \\
\text { loucura, não teve fase } \\
\text { de comemoração } \\
\text { intermediária não. } \\
\mathrm{R}_{2} \mathrm{C}:[\ldots . .] \text { comemorada } \\
\text { formalmente não. }\end{array}$ \\
\hline
\end{tabular}

Fonte: Elaborado pelos autores

\section{Relações interpessoais}

Com base na análise das opiniões dos entrevistados presentes nas respostas às questões relacionadas às relações interpessoais (Bloco 5), foram estruturadas as categorias que evidenciaram estas questões geridas durante a implementação das mudanças:

- "comunicação": processo de comunicação ocorrido durante a implementação dos projetos feita pelos entrevistados, desdobrada na subcategoria "escrita e oral"; 
- "motivação": a prontidão das pessoas envolvidas na implementação em persistir contra dificuldades e frustrações, desdobrada nas subcategorias "aumento de conhecimento", "gratificação pessoal" e "desenvolvimento de relacionamentos".

- "treinamento": os tipos de treinamentos realizados durante a implementação cujo escopo relacionou-se à "sistema" e "processo" sendo, portanto, desdobrados em subcategorias.

O Quadro 4 ilustra a elaboração das categorias e sub-categorias referentes às relações interpessoais.

Quadro 4 - Categorização das relações interpessoais

\begin{tabular}{|c|c|c|c|c|}
\hline \multirow[b]{2}{*}{ CATEGORIA } & \multirow[b]{2}{*}{$\begin{array}{c}\text { SUB- } \\
\text { CATEGORIA }\end{array}$} & \multicolumn{3}{|c|}{ TEMA } \\
\hline & & EMPRESA A & EMPRESA B & EMPRESA C \\
\hline Comunicação & Escrita e Oral & $\begin{array}{l}\mathrm{R}_{1} \mathrm{~A}:[\ldots] \text { aconteceu por } \\
\text { telefone, e-mail, vídeo, } \\
\text { conferência, nas } \\
\text { reuniões de } \\
\text { mapeamento e folllow- } \\
\text { up. Também havia as } \\
\text { atas das reuniões [...]. } \\
\mathrm{R}_{2} \mathrm{~A}:[. . .] \text { Havia } \\
\text { reuniões de } \\
\text { alinhamento [...]. [...] } \\
\text { havia atas de reunião } \\
\text { que eram distribuídas } \\
\text { junto com o } \\
\text { cronograma.. } \\
\mathrm{R}_{3} \mathrm{~A}:[. . .] \text { A gente fazia } \\
\text { muito conference call, } \\
\text { as cobranças eram via } \\
\text { e-mail. [...] }\end{array}$ & $\begin{array}{l}\mathrm{R}_{1} \mathrm{~B}:[\ldots] \text { foi através de } \\
\text { workshops, reuniões, } \\
\text { comunicação escrita, } \\
\text { acompanhamento via } \\
\text { e-mail, por telefone. } \\
\mathrm{R}_{2} \mathrm{~B}: \text { [...] A cada final } \\
\text { de fase eram reunidos } \\
\text { todos os gerentes e os } \\
\text { envolvidos para } \\
\text { mostrar o status do } \\
\text { projeto e durante as } \\
\text { fases eram feitas atas } \\
\text { de reuniões, progress } \\
\text { reports, por e-mail. } \\
\mathrm{R}_{3} \mathrm{~B}:[. . .] \text { Eram } \\
\text { divulgados e-mails, [...] } \\
\text { progress report [...] } \\
\text { reuniões [...]. }\end{array}$ & $\begin{array}{l}\mathrm{R}_{1} \mathrm{C}:[\ldots] \text { tínhamos } \\
\text { reuniões semanais } \\
{[\ldots] \text { reuniões mensais }} \\
\text { com a gerência. [...] } \\
\text { atas de reuniões, } \\
\text { cronogramas que } \\
\text { eram apresentados. } \\
{[\ldots . .] \text { no dia-a dia, }} \\
\text { contato verbal. } \\
\mathrm{R}_{2} \mathrm{C}:[\ldots] \text { Nós } \\
\text { fazíamos reuniões } \\
\text { desde o início [...]. } \\
{[\ldots] \text { a gente fazia ata }} \\
\text { porque era para } \\
\text { formalizar o que } \\
\text { havia sido dito.[...] a } \\
\text { gente ia conversar } \\
\text { diretamente com as } \\
\text { pessoas. }\end{array}$ \\
\hline
\end{tabular}

$\mathrm{R}_{1} \mathrm{~A}:[\ldots]$ oportunidade $\quad \mathrm{R}_{2} \mathrm{~B}:[\ldots]$ aprender

de adquirir novos

bastante coisa.

$\begin{array}{lll}\text { Motivação } & \begin{array}{l}\text { Aumento de } \\ \text { Conhecimento }\end{array} & \begin{array}{l}\mathrm{R}_{3} \mathrm{~A}[\ldots] \text { Foi um } \\ \text { aprendizado muito } \\ \text { grande. }\end{array}\end{array}$

\begin{tabular}{llll}
\hline & $\mathrm{R}_{3} \mathrm{~A}:[\ldots]$ a vinda da & $\mathrm{R}_{1} \mathrm{~B}:[\ldots]$ ajudar a & $\mathrm{R}_{1} \mathrm{C}:[\ldots]$ gratificação \\
& fábrica, da linha de & empresa a ser mais & de ter implementado \\
& produção, eu senti um & competitiva, criar & um projeto desse \\
& grande impacto da & novos negócios, estou & nível. \\
& minha existência. [...] a & me sentindo seguro. & \\
Gratificação & sobrevivência da & $\begin{array}{l}\mathrm{R}_{2} \mathrm{~B}:[\ldots] \text { realização } \\
\text { pessoal }\end{array}$ & \\
fessoal & fábrica. & & \\
& & &
\end{tabular}




\begin{tabular}{|c|c|c|c|c|}
\hline & $\begin{array}{l}\text { Desenvolvimen-to } \\
\text { de Relaciona- } \\
\text { mentos }\end{array}$ & & $\begin{array}{l}\mathrm{R}_{2} \mathrm{~B}:[\ldots] \text { Trabalhar } \\
\text { com a empresa inteira, } \\
\text { ver o todo, relacionar } \\
\text { com as pessoas. }\end{array}$ & \\
\hline \multirow[t]{2}{*}{ Treinamento } & Sistemas & $\begin{array}{l}\mathrm{R}_{1} \mathrm{~A}:[\ldots] \text { também um } \\
\text { treinamento na } \\
\text { ferramenta. }\end{array}$ & $\begin{array}{l}\mathrm{R}_{1} \mathrm{~B}:[\ldots] \text { Treinamentos } \\
\text { formais existiram } \\
\text { especificamente só } \\
\text { para a ferramenta } \\
\text { sistêmica, mas não para } \\
\text { os processos. } \\
\mathrm{R}_{2} \mathrm{~B}:[\ldots] \text { o treinamento } \\
\text { foi bem específico para } \\
\text { a ferramenta. } \\
\mathrm{R}_{3} \mathrm{~B}:[\ldots] \text { com relação à } \\
\text { ferramenta Recof. }\end{array}$ & $\begin{array}{l}\mathrm{R}_{2} \mathrm{C}:[\ldots] \\
\text { Treinamento no } \\
\text { sistema }[\ldots] .\end{array}$ \\
\hline & Processo & $\begin{array}{l}\mathrm{R}_{1} \mathrm{~A}:[\ldots] \text { foram os } \\
\text { workshops de } \\
\text { apresentação e de } \\
\text { mapeamento de } \\
\text { processo [...]. }\end{array}$ & & $\begin{array}{l}\mathrm{R}_{1} \mathrm{C}:[\ldots] \text { Se não } \\
\text { tivesse essa mudança, } \\
\text { esse treinamento, o } \\
\text { pessoal não iria } \\
\text { colocar em prática o } \\
\text { que teria que } \\
\text { acontecer. } \\
\mathrm{R}_{2} \mathrm{C}:[\ldots] \text { treinamento } \\
\text { sobre as atividades } \\
{[\ldots] \text { nos processos. }}\end{array}$ \\
\hline
\end{tabular}

Fonte: Elaborado pelos autores

\section{Análise dos resultados}

\section{Aspectos relevantes da gestão da mudança}

As considerações feitas neste item tomaram por base as categorizações elaboradas anteriormente, em conexão com o primeiro objetivo deste artigo. É oportuno ressaltar a interconexão entre alguns dos aspectos analisados. As falas colocadas a título de ilustração foram selecionadas de acordo com a relevância para as considerações.

Com relação ao planejamento das atividades, o cronograma foi um instrumento de grande presença e importância, confirmado pelos depoimentos a seguir:

Empresa A - $\mathrm{R}_{1} \mathrm{~A}$ : “[...] a existência de um grupo de programa..., com atividades e prazos definidos foi muito importante".

Empresa $\mathrm{B}-\mathrm{R}_{2} \mathrm{~B}$ : “[...] prazos, metas, objetivos, o que tem que fazer, isso era claro e auxiliou no atingimento dos objetivos".

Empresa $\mathrm{C}-\mathrm{R}_{1} \mathrm{C}$ : “[...] com certeza o cronograma auxiliou no atingimento dos objetivos através do acompanhamento e planejamento das atividades. Ele existia de fato e era muito utilizado e consultado, não foi algo que a gente construiu e esqueceu".

Com relação ao comprometimento, ele está relacionado aos aspectos interpessoais de motivação e da comunicação, este último identificado como um aspecto adicional do processo, presente na implementação:

Empresa A - $\mathrm{R}_{2} \mathrm{~A}$ : “[...] um alto de grau de comprometimento. Quando houve necessidade de trabalho extraordinário, estava todo mundo disponível. De fato vestiram a camisa”.

Empresa B - $\mathrm{R}_{2} \mathrm{~B}$ : “[...] as pessoas também estavam comprometidas e os motivos que fizeram com que as pessoas estivessem engajadas foi a informação". 
Empresa $\mathrm{C}-\mathrm{R}_{1} \mathrm{C}$ : “[...] por mais difícil que pareça, por mais impossível até que pareça ser, se todo mundo estiver engajado, imbuído na mesma causa, a coisa acontece".

Quanto à cultura para a mudança, esta foi promovida por meio da exposição dos benefícios da realização de alterações e da implementação de inovações de processos:

Empresa A - $R_{1} A$ : “[...] a experiência adquirida em projetos de mudança de processo, ou seja, a expertise desenvolvida para a gestão da mudança".

Empresa $\mathrm{C}-\mathrm{R}_{1} \mathrm{C}$ : “[...] qualquer mudança de processo por mais que você ache que essa mudança não tem impacto nenhum no Recof, ela tem, então o departamento Recof tem de ser questionado".

No aspecto do envolvimento das pessoas para participarem do projeto Recof, a identificação adequada das pessoas com a experiência anterior, com o desenvolvimento e melhoria de processos foi um dos pontos altos nas mudanças, conforme os depoimentos:

Empresa $\mathrm{A}-\mathrm{R}_{1} \mathrm{~A}$ : “[...] envolvimento das pessoas com a expertise no processo - das pessoas-chavepara o correto mapeamento dos processos e hand-over das atividades/conhecimento relacionadas aos processos para o grupo".

Empresa B - $\mathrm{R}_{3} \mathrm{~B}$ : “[...] o envolvimento das pessoas-chave das áreas que entenderam a necessidade do Recof para a empresa [...]".

Empresa $\mathrm{C}-\mathrm{R}_{1} \mathrm{C}$ : “[...] para cada área de negócio foi definido um focal point e essa pessoa deveria ter no mínimo um nível de supervisão e teria que acompanhar as reuniões, entender quais eram as novas necessidades do Recof e implementar isso".

Com relação ao suporte às mudanças, a coalizão administrativa, outro aspecto adicional identificado, foi apontado pelos entrevistados como crucial ao processo:

Empresa A - $\mathrm{R}_{1} \mathrm{~A}$ : “[...] sensibilização da Diretoria e, consequentemente, apoio na implementação”.

Empresa B $-\mathrm{R}_{3} \mathrm{~B}$ : “[...] se tinha algum showstopper, eles sempre corriam atrás para estar resolvendo para que não impactasse o projeto. [...] o corpo diretivo e gerência estavam realmente engajados no projeto e estavam contribuindo para que as coisas acontecessem da melhor forma possível".

Empresa $\mathrm{C}-\mathrm{R}_{1} \mathrm{C}$ : “[...] a metodologia utilizada pelos gerentes de estarem sempre próximos e envolvidos no projeto contribuiu bastante para o atingimento do objetivo [...]”.

A existência de método foi outro aspecto apontado como facilitador das mudanças, conforme os depoimentos:

Empresa A - R1A: "[...] tudo isso, todas essas atividades oriundas e previstas no método foram fundamentais para o atingimento dos objetivos".

Empresa B - $\mathrm{R}_{1} \mathrm{~B}$ : “[...] uma estrutura de implementação de projeto muito bem acompanhada porque, se não tivesse isso também, a gente não teria conseguido. Me refiro ao método, porque é muito fácil você falar que vai fazer um projeto e vai fazendo, vai fazendo, vai fazendo, mas, quando você tem um método, você segue aquele caminho e ele exige que você não corte processos, steps, que depois irão fazer falta mais para frente".

Assim, considerando as falas dos entrevistados, pode-se assumir que o planejamento das atividades, o comprometimento, o envolvimento dos participantes e o suporte da alta direção foram os aspectos mais relevantes envolvidos na gestão da mudança para a eficácia dos resultados. 


\section{Fases do processo de mudança realizadas pelas empresas}

Há evidências de que nas empresas A, B e C a gestão da mudança oriunda da adoção do Recof tenha ocorrido através da execução, em fases, do processo de mudança (HAYES, 2002), mesmo que de maneira pouco consciente.

A primeira fase, identificação da necessidade de mudança, (KIRKBRIDGE, 1998) ocorreu nas três empresas, porém o fato gerador foi diferente entre elas. Essas diferenças são evidenciadas nos seguintes depoimentos dos entrevistados:

\section{Empresa A:}

$\mathrm{R}_{1} \mathrm{~A}$ : “[...] a empresa queria trazer uma linha de produção para o Brasil, porém, para tanto, precisava ter custos menores e ser mais competitiva [...]".

$\mathrm{R}_{2} \mathrm{~A}$ : “[...] o planejamento estratégico que tinha estratégias voltadas ao aumento de exportação”.

Empresa B - $\mathrm{R}_{1} \mathrm{~B}$ : “[...] ocorreu pela seguinte situação: um nível de alta carga tributária de material importado que a gente tinha na época e que a gente identificou essa oportunidade de redução de custo. A gente identificou que esse projeto, esse incentivo do governo, poderia trazer uma redução de impostos e, com isso, criar ou aumentar uma oportunidade de exportação porque a gente tinha um volume muito pequeno na época. Então, foi uma busca por redução de custo e novas oportunidades de negócios, no caso, especificamente, de aumento da exportação”.

Empresa $\mathrm{C}-\mathrm{R}_{1} \mathrm{C}$ : “[...] basicamente foi motivado pelo ganho financeiro. [...] quem tocou o projeto adiante foi a área de finanças, porque, a princípio, era bem ligado aos ganhos financeiros e todo mundo já tinha esse conhecimento que o Recof trazia."

A segunda fase, início do processo de mudança, (STICKLAND, 1998) aconteceu nas três empresas por meio da execução de atividades similares de entendimento da legislação, elaboração de business case, identificação das pessoas e realização de kickoff, conforme os depoimentos a seguir.

Quanto ao entendimento da legislação:

Empresa A - $\mathrm{R}_{3} \mathrm{~A}$ : “[...] Primeiro procuramos nos informar, conhecer a legislação. As alternativas para implantar o Recof não eram muito grandes".

Empresa B - $\mathrm{R}_{1} \mathrm{~B}$ : “[...] O início foi bem interessante. Primeiro é o entendimento do que está por trás da legislação e como isso impacta nos processos existentes na empresa [...]”.

Empresa $\mathrm{C}-\mathrm{R}_{1} \mathrm{C}$ : “[...] Então, o início foi bem a análise da legislação, tentar entender um pouquinho que "bicho" era esse, se a empresa tinha condições de atender aos requisitos, quais eram esses requisitos, né?!, mapear, ver se a gente conseguia atender a tudo isso [...]".

Quanto à elaboração de business case:

Empresa A - $\mathrm{R}_{1} \mathrm{~A}$ : “[...] mostramos os benefícios internos da implementação, os ganhos financeiros, e também os desafios da implementação em empresa de grande porte”.

Empresa $\mathrm{B}-\mathrm{R}_{1} \mathrm{~B}$ : "[...] você tem que vender a ideia de que você vai mudar todos os processos da empresa, porque isso vai trazer um benefício "x" e uma oportunidade de melhoria de negócio. Então, primeiro você tem que vender a ideia para o alto escalão, baseado em business case e todo o levantamento que a gente fez".

Empresa $\mathrm{C}-\mathrm{R}_{1} \mathrm{C}$ : “[...] então, depois dessa análise da legislação chegou-se à conclusão de que era viável implementar e aí foi feito um business case, baseado nos dados de que a gente dispunha na época. Esse business case mostrava assim vantagens financeiras que brilhavam aos olhos de qualquer um $[\ldots] "$. 
Quanto à identificação das pessoas:

Empresa $A-R_{1} A$ : "[...] uma vez identificados os processo envolvidos no escopo do Recof, foram identificados os process experts de cada processo e feita a negociação desses recursos".

Empresa B - $\mathrm{R}_{1} \mathrm{~B}$ : “[...] foram identificadas pela senioridade do cargo, ou seja, que

conheciam os processos da sua área. Em um primeiro momento a gente colocou todas as áreas da empresa. Depois a gente verificou qual era o grau de interação que existia para cada área e depois, em um terceiro step, identificou quais eram as áreas e as pessoas com mais senioridade naquele processo para trabalhar no projeto".

Empresa $\mathrm{C}-\mathrm{R}_{1} \mathrm{C}$ : “[...] para cada área de negócio foi definido um focal points e essa pessoa deveria ter no mínimo um nível de supervisão e teria que acompanhar as reuniões, entender quais eram as novas necessidades do Recof e implementar isso".

Quanto ao kick-off:

Empresa A - $\mathrm{R}_{1} \mathrm{~A}$ : “[...] foi realizado um kick-off, onde foi apresentado o cronograma, a importância do Recof, papéis e responsabilidades e, a partir daí, se iniciou o mapeamento dos processos".

Empresa B - $\mathrm{R}_{2} \mathrm{~B}$ : “[...] todo início de projeto é feito um kick-off, então, por exemplo, você mostra o business case, você mostra como vai ser desenvolvido o projeto e pelo menos um cronograma básico, em alto nível, para que todos os envolvidos, ou quem está presente na sala possa estar de acordo com o fato de estar indo para a frente [...]".

Empresa $\mathrm{C}-\mathrm{R}_{1} \mathrm{C}$ : “[...] teve o kick-off onde foram mostrados os ganhos financeiros, uma ideia bem macro de cronograma e o ganho logístico".

A terceira fase, do diagnóstico (STICKLAND, 1998) (SIMS, 2002), ocorreu nas três empresas, de maneira similar, mas com incertezas sobre o futuro, de acordo com os depoimentos dos entrevistados:

Empresa A - $\mathrm{R}_{1} \mathrm{~A}$ : “[...] algumas mudanças ocorreram e algumas atividades foram adaptadas ao longo do processo, porque a visão detalhada do que seria mudado foi sendo descoberta durante a implementação".

Empresa $\mathrm{B}-\mathrm{R}_{2} \mathrm{~B}$ : “[...] no início do projeto nós sabíamos que tínhamos muitos desafios em relação a essa mudança, mas ela não estava clara para a gente assim: olha, você vai mudar isso, isso, isso e isso, e os papéis estavam bem distribuídos e nós só tínhamos o trabalho de fazer com que as pessoas entendessem. Não era bem isso".

Empresa $\mathrm{C}-\mathrm{R}_{2} \mathrm{C}$ : “[...] foi sendo descoberta aos poucos porque na época não tinha ninguém que conhecia o Recof a ponto de dizer o que significava essa mudança em termos, tanto de processo, como de sistema, porque é algo que exige uma mudança na base dos processos".

A quarta fase, planejamento e preparação da implementação, foi executada coincidentemente nas três empresas por meio da elaboração de cronogramas e, até mesmo, de organograma, conforme os depoimentos:

Empresa B - $\mathrm{R}_{2} \mathrm{~B}$ : “[...] o cronograma do projeto, que nós dividimos em fases. Eu não tenho na minha cabeça as fases do projeto, mas o principal de que eu me lembro agora em relação ao projeto é que tem toda a parte de análise que a gente gastou um tempo que garantiu depois, mesmo sendo em um curto tempo, a parte de execução".

Empresa $\mathrm{C}-\mathrm{R}_{1} \mathrm{C}$ : “[...] Foi feito um cronograma de implementação onde a parte de sistemas caminhava um pouco mais avançada do que a parte de mudança de processo, porque havia algumas coisas que dependia de: vai ter que mudar, mas tem que esperar implementar para poder mudar. Então 
a gente já "estartava", já desenvolvia esse conhecimento do que teria que ser mudado, mas ele ainda não poderia ser iniciado e foi meio que preparando para o que iria acontecer [...]".

Empresa B - $\mathrm{R}_{2} \mathrm{~B}$ : “[...] nós utilizamos o método de gerenciamento de projeto da empresa - Props - que é para estruturar o projeto, para fazer o organograma [...]. [...] Foi explicado e foi mostrado de forma bem...,não vou dizer exaustiva, mas foi mostrado e divulgado".

Empresa C- $\mathrm{R}_{1} \mathrm{C}$ : "[...] tinha um organograma que era em um nível bem alto. Começava assim mesmo no diretor da empresa e esse organograma tinha todo o detalhamento da parte de sistemas que também tinha uma gerência praticamente $100 \%$ para a implementação do Recof no início, tinha organograma na parte desse departamento que eu te falei que foi criado que na época era na área de finanças, tinha o organograma também da software house que desenvolveu".

A quinta e última fase, a da implementação das mudanças propriamente ditas, realizada em todas as empresas também por meio da execução de atividades similares: de mapeamento dos processos, execução dos planos de ação e desenvolvimento de sistemas, teve os seguintes objetivos:

Empresa A - $\mathrm{R}_{1} \mathrm{~A}$ : “[...] no mapeamento dos processos eram identificados os impactos e alterações nos processos correntes".

Empresa B - $\mathrm{R}_{1} \mathrm{~B}$ : “[...] o objetivo era alinhamento dos processos existentes e novos processos [...]”.

Empresa $\mathrm{C}-\mathrm{R}_{1} \mathrm{C}$ : “[...] A gente pegava com base no que a gente tinha na legislação para ter um argumento mais forte, para ser mais fácil de controlar os questionamentos que poderiam acontecer, meio assim: olha, tá na lei, não tem escapatória. Aí a gente montava um desenho do processo AS IS e o processo futuro como teria que ser para atender o Recof. [...] mapeamos os processos de todas as áreas. Inclusive a gente refez os procedimentos".

Foi possível verificar que, mesmo havendo diferenças no modo de execução, os cinco primeiros passos do processo de mudança propostos por Hayes (2002) foram realizados por intermédio de atividades similares. Contudo, não há evidências de que o sexto e último passo - revisão da implementação - tenha sido efetivamente realizado. Segundo Kotter (2000), ignorar alguma etapa do processo, ou adiantar-se demais sem ter uma base sólida, pode produzir resultados insatisfatórios.

Contudo, outros aspectos também foram apontados pelos entrevistados como relevantes para as mudanças.

Um deles, a criação do senso de urgência (ADIZES, 1995), segundo o consenso entre os entrevistados, tirou as empresas da inércia e efetivamente mobilizou os envolvidos para as mudanças:

Empresa A - $\mathrm{R}_{1} \mathrm{~A}$ : “[...] como eu disse, (vírgula) nós queríamos trazer uma linha de produção para o Brasil e isso só foi viabilizado com a implementação do Recof devido aos menores custos e agilidade da operação. Se não tivéssemos o Recof, a existência da operação fabril [...] estaria em risco".

Empresa B - $\mathrm{R}_{1} \mathrm{~B}$ : “[...] com o projeto tínhamos a possibilidade de crescer, [...] ter um negócio a mais e, com isso, vinha também a segurança do emprego, porque, se a empresa vai bem, o funcionário vai bem também. Então está implícito que eu estou trabalhando em um projeto que vai ajudar a empresa a ser mais competitiva, criar novos negócios, então, eu estou me sentindo seguro e isso é bom para mim e também para a empresa.

Empresa A - $\mathrm{R}_{2} \mathrm{~A}$ : “[...] A maioria se comprometeu e comprou a ideia, até por

perceberem que era a única alternativa que nós tínhamos para nos tornarmos

exportadores para valer". 
Empresa $\mathrm{C}-\mathrm{R}_{2} \mathrm{~A}$ : “[...] ajudar a gente porque existia ganho no tempo de liberação da mercadoria, ganho de cashflow e tal e eles acharam que era legal ter o Recof, que iria ajudar a agilizar nossa operação".

Quando questionados sobre a existência de uma coalizão administrativa para a tomada de decisão, verificou-se uma unanimidade nas respostas sobre a formação de um grupo com autoridade suficiente para liderar a implementação das alterações de processos nas diferentes empresas.

Empresa $\mathrm{A}-\mathrm{R}_{3} \mathrm{~A}$ : “[...] tinha uma voz que é isso e pronto, tanto para o bem como para o mal. Então, se chegasse uma pessoa e falasse vamos melhorar o processo de recebimento e ele falasse não, vamos ficar como está, era tanto para o bem como para o mal do projeto".

Empresa $B-R_{2} B$ : “[...] só foi através dele que a gente conseguiu, sem ele ficaria difícil. Eles eram envolvidos em momento de decisão, momentos onde nós não tínhamos como, às vezes, até argumentar. A argumentação tinha que ser feita por ele e o papel de decisão, de vamos ou não vamos, era dele. [...]Se num determinado momento a gente precisasse parar o projeto para poder tomar uma decisão, como aconteceu, a gente teria esse respaldo".

Empresa $\mathrm{C}-\mathrm{R}_{1} \mathrm{C}$ : “[...] Quando dava algum conflito em alguma área, quando alguma área estava um pouco mais atrasada no que deveria fazer, a gerência intermediária (ou a gerência intervinha?) conseguia fazer a coisa acontecer”.

Outra menção relevante feita pelos entrevistados foi de que, embora tenham sido estabelecidas metas intermediárias que foram cumpridas, não houve qualquer promoção de vitórias durante o processo:

Empresa $\mathrm{A}-\mathrm{R}_{1} \mathrm{~A}$ : “[...] as comemorações ocorreram no final do projeto, depois da habilitação, através da realização de um evento com a participação da presidência, mídia, etc. Não ocorreram comemorações durante o projeto".

Empresa $\mathrm{B}-\mathrm{R}_{1} \mathrm{~B}$ : “[...] eu acho que isso é uma lessons learned para nós, porque a gente não comemorou muito. A gente poderia ter comemorado mais de uma maneira, que isso fosse um incentivo para as próximas fases. Naquele afã de a gente ver o final, final mesmo do projeto, a gente não comemorou ações intermediárias. No final teve uma comemoração, um almoço, tudo mais".

Empresa $\mathrm{C}-\mathrm{R}_{1} \mathrm{C}$ : "[...] na época em que a gente deu o pontapé inicial foi meio traumático. Esse pessoal do Recof em si trabalhou praticamente 1 ano no sábado, domingo e feriado. Então foi meio loucura, não teve essa fase de comemoração intermediária não. Mesmo porque o Recof era todo bonito, era lindo, maravilhoso, mas ninguém tinha visto. Então, foi só quando a gente teve a homologação do sistema".

Assim, ficou evidenciado que os aspectos adicionais relevantes ocorridos foram a criação do senso de urgência e a implementação de uma coalizão administrativa.

\section{Aspectos referentes às relações interpessoais durante a implementação das mudanças}

Com referência à comunicação (HAYES, 2002), ficou claro que foram utilizados diferentes canais, tanto verbais quanto escritos:

Empresa A - $\mathrm{R}_{3} 1 \mathrm{~A}$ : “[...] A comunicação aconteceu por telefone, e-mail, vídeo

conferência, nas reuniões de mapeamento e follow-up. Também havia as atas das reuniões que eram enviadas aos participantes".

Empresa $\mathrm{B}-\mathrm{R}_{2} \mathrm{~B}$ : “[...] A cada final de fase eram reunidos todos os gerentes e os envolvidos para mostrar o status do projeto e durante as fases eram feitas atas de reuniões, progress reports, por e-mail, e em alguns pessoais". 
Empresa $\mathrm{C}-\mathrm{R}_{1} \mathrm{C}$ : “[...] tínhamos reuniões semanais [...] reuniões mensais com a gerência. [...] atas de reuniões, havia todos os cronogramas que eram apresentados. [...] no dia-a dia também havia esse contato verbal".

No que tange à motivação para mudança, que consiste na prontidão das pessoas em persistir frente a dificuldades e frustrações (STICKLAND, 1998), a gratificação pessoal foi um fator motivador característico nas três empresas.

Empresa $\mathrm{A}-\mathrm{R}_{3} \mathrm{~A}$ : “[...] eu participei de um dos eventos que foi comemorando a vinda da fábrica, da linha de produção, então isso, naquele momento eu senti um grande impacto da minha existência na empresa, entendeu? Eu falei: nossa, eu estou aqui para isso! Eu não acredito! Entendeu?"'

Empresa B - $R_{2} B$ : “[...] Não, eu não vi isso. Eu tinha como realização pessoal estar implantando, eu queria estar implantando".

Empresa $\mathrm{C}-\mathrm{R}_{1} \mathrm{C}$ : “[...] Muito gratificante porque foi assim: é isso aqui, tá pronto, foi homologado pela Receita Federal e fui eu que fiz. Então, essa foi a melhor parte: a gratificação de ter implementado um projeto desse nível e um projeto que hoje é uma das condições da empresa ter a fábrica no país"

Também foram consideradas relevantes a oportunidade de aumento de conhecimentos e a possibilidade de desenvolvimento de relacionamentos:

Empresa $A-R_{1} A$ : “[...] o projeto foi uma oportunidade de adquirir novos conhecimentos. Em termos de gerenciamento, o profissional de comércio exterior passou a se preocupar com o processo de supply chain, não somente com as operações de importação e exportação, mas também com produção, reparo, etc".

Empresa $\mathrm{B}-\mathrm{R}_{2} \mathrm{~B}$ : “[...] trabalhar com a empresa inteira, ver o todo, relacionar com as pessoas, apresentar, então, para mim eu aprendi bastante coisa. Foi muito legal".

Quanto aos treinamentos (SIMS; SIMS, 2002) a sua realização variou de empresa para empresa, mas ocorreram treinamentos sistêmicos e de processos:

Empresa $\mathrm{B}-\mathrm{R}_{1} \mathrm{~B}$ : “[...] treinamentos formais existiram especificamente só para a ferramenta sistêmica, mas não para os processos. Para os processos foram feitos os procedimentos".

Empresa $C$ - $\mathrm{R}_{1} \mathrm{C}$ : “[...] foram feitos sim. [...] Se não tivesse esse treinamento, o pessoal não iria colocar em prática o que tinha que acontecer".

Hayes (2000) aponta que, durante um processo de mudança, é importante identificar com antecedência como as pessoas envolvidas responderão à mudança e, consequentemente, definir estratégias para tratar os seus interesses pessoais. Nesse sentido, em nenhuma das empresas foi verificada a existência de um plano visando facilitar a adaptação individual, ou seja, não houve evidências de que os interesses pessoais (HAYES, 2002) dos participantes tenham sido levados em consideração, tal como preconizado na literatura.

Assim, em relação às questões interpessoais, verificou-se que estas foram tratadas por meio de comunicação verbal e escrita, pela motivação voltada à gratificação pessoal e pela execução de treinamentos nas empresas, mas sem levar em conta os interesses pessoais dos participantes.

\section{Considerações finais}

Uma das primeiras considerações que podem ser feitas é de que houve poucas divergências ou variações entre as práticas de gestão da mudança nas três empresas dos entrevistados. Isso indica que os procedimentos do Recof sejam suficientemente detalhados e especificados, ou que os ambientes das empresas apresentem certa homogeneidade. 
Seguindo-se à risca o modelo de processo de mudança proposto por Hayes (2002), por exemplo, não houve evidências de que alguns passos essenciais ao processo de mudança ocorreram de maneira explícita nas empresas estudadas, como a sexta fase do processo de mudança - "revisão da implementação", a elaboração de um plano de ação para tratar os interesses pessoais (questão interpessoal) e as promoções de vitórias em curto prazo (item adicional às fases do processo de mudança). Levando-se em conta os autores citados no Referencial Teórico, aparentemente questões importantes foram desconsideradas durante a gestão da mudança e, consequentemente, isto deveria ter influenciado negativamente na sua realização. Contudo, apesar de não ter sido seguido todo o roteiro preconizado pela literatura, a mudança foi efetivamente implementada em cada uma das empresas em condições de poderem adotar o Recof, que é um indicador mínimo do seu sucesso. Isso levanta a dúvida se efetivamente a execução de todos os passos relacionados à gestão da mudança preconizados pelos diversos autores, de maneira genérica, é indispensável para que esta seja efetivada. Nesse ponto são cabíveis algumas conjecturas. Com relação à revisão da implementação, possivelmente perante procedimentos e metas tão explícitos, o confronto do previsto com o realizado efetivamente pode ter sido facilitado, não representando dificuldades que merecessem comentários dos entrevistados. Quanto à negociação de interesses pessoais, é provável que este tenha ocorrido de maneira tácita, por meio do envolvimento, comprometimento e suporte da direção, diante de um fator externo e desconhecido, até então, para todos dentro das empresas que era o Recof. Sobre a promoção de vitórias não terem ocorrido, há duas considerações a fazer; uma delas é a clareza dos efeitos aparentemente positivos provocados pelo Recof sobre o ambiente interno, já comentado anteriormente; e a outra é que a cultura vigente nas empresas no Brasil, mesmo sendo essas de capital estrangeiro, talvez não seja muito receptiva a práticas como esta.

Uma terceira consideração a ser feita é de que a criação do senso de urgência e a coalizão administrativa, aparentemente, foram os influenciadores das prioridades dadas à implementação dos projetos em todas as empresas. Kotter (2001) afirma que a evidência de crise, problemas ou oportunidades são fundamentais para a realização da mudança, pois cria a energia necessária para a transformação, o que foi corroborado neste estudo. A urgência revelou-se tão importante quanto a coalizão entre os gestores dos projetos e a direção das empresas, fazendo com que a autoridade e poder para a tomada de decisões tenha ajudado na obtenção do comprometimento e no envolvimento das pessoas na mudança. Essa combinação aparentemente foi um facilitador do cumprimento do cronograma e, consequente, do atingimento das metas nas três empresas. A literatura expõe a importância da formação de um grupo com autoridade para liderar a mudança, mas no âmbito deste estudo ficou evidente que o envolvimento e comprometimento do alto escalão foi um fator decisivo.

Uma quarta consideração, referente aos aspectos interpessoais, diz respeito aos resultados positivos obtidos com o envolvimento das pessoas como consequência dos treinamentos e da troca de informações promovidos durante a execução do projeto. Diante disso, pode-se assumir que, em um processo de mudanças, esses aspectos devem ser a essência da estratégia, pois influenciam diretamente no clima entre os participantes. A literatura consultada não faz menção à gratificação pessoal e ao alinhamento entre interesses pessoais e corporativos como fator motivador, mas neste estudo ambos se revelaram importantes.

O presente artigo buscou contribuir para o aumento do conhecimento sobre como a gestão da mudança é realizada em ambientes altamente dinâmicos, cuja implementação de alterações de processo faz parte do cotidiano das empresas. No que tange à contribuição prática, este estudo pretendeu ressaltar os aspectos relevantes na gestão da mudança em ambientes de mudanças em processos geradas por necessidades estratégicas. Também buscou gerar informações aos gestores de mudança sobre os pontos de atenção a serem considerados durante a execução desse tipo de projetos, principalmente quando direcionados a mercados de grandes transformações tecnológicas como é o das telecomunicações.

Finalizando, como se trata de um universo amostral não probabilístico, restrito ao microambiente de processo Recof nas empresas de telecomunicações, os resultados deste estudo não podem ser generalizados. Por isso, recomenda-se sua replicação em outros setores que utilizam o Recof, como por exemplo, aeronáutico, automobilístico, para corroboração ou refutação das conclusões e também sua comparação entre diferentes setores econômicos. Sugere-se também a ampliação para outros microambientes de processo, visando ampliar o conhecimento sobre os fenômenos referentes à gestão da mudança estudados. 
Outra limitação a ser considerada está relacionada à sua abordagem qualitativa, que sempre enfrenta a dificuldade de demonstrar a sua validade e confiabilidade. Para minimizar essa limitação foram respeitadas as regras de validade e confiabilidade da análise de conteúdo de Bardin (2000) e Richardson (1999), onde os resultados brutos foram tratados de maneira a serem significativos e válidos (FLICK, 2004). Neste sentido, recomenda-se uma abordagem quantitativa no seu desdobramento, submetendo os resultados a provas estatísticas e testes de validação. 


\section{Referências}

AAKER, David A.; KUMAR, Vinay; DAY, George S. Pesquisa de marketing. São Paulo: Atlas, 2004.

ADIZES, Ichak. Gerenciando as mudanças: o poder da confiança e do respeito mútuos na vida pessoal, familiar, nos negócios e na sociedade. $2^{\mathrm{a}}$ ed. São Paulo: Pioneira, 1995.

ANDERSON, Dean; ANDERSON, Linda S. Beyond change management: advanced strategic for today's transformational leaders. San Francisco: Jossey-Bass, 2001.

ANUÁRIO TELECOM. 2005. São Paulo: Plano Editorial, 2005.

BARDIN, Laurence. Análise de conteúdo. Lisboa: Edições 70, 2000.

BELASCO, James A. Ensinando o elefante a dançar: como estimular mudanças na sua empresa. Rio de Janeiro: Campus, 1992.

BURNES, Bernard. Managing change and changing managers from ABC to XYZ. Journal of Management Development, v. 22, p. 627-642, 2003.

DUCK, Jeanie D. Gerenciando a mudança: a arte do equilíbrio. In: MUDANÇA: Harvard Business Review. Trad. Afonso Celso da Cunha Serra. Rio de janeiro: Campus, 1999.

ERICSSON TELECOMUNICAÇÕES. Site oficial da empresa. Disponível em: <http://www.ericsson.com/br/>. Acesso em: 22 mar. 2006.

FLICK, Uwe. Uma introdução à pesquisa qualitativa. Porto Alegre: Bookman, 2004.

FRANCESCHINI NETO, Menotti A. A importância do controle informatizado no regime

Recof. Disponível em: <http://www.recof.com.br>. Acesso em: 21 ago. 2005.

GIL, Antônio C. Como elaborar projetos de pesquisa. São Paulo: Atlas, 2002.

GRANVILLE, David. Developing logistics potential through people. Logistics Information

Management, v. 9, n. 1, p. 39-42, 1996.

HAYES, John. The theory and practice of change management. New York: Palgrave, 2002.

HOAG, Bruce G., RITSCHARD, Hans V.; COOPER, Cary L. Obstacles to effective organization change: the underlying reasons. Leadership \& Organization Development Journal, v. 23, n. 1; p. 6-15, 2002.

HUCZYNSKI, Andrzej; BUCHANAN, David. Organizational behaviour. New York: Prentice Hall Press, 1997.

KIRKBRIDGE, Paul. Gerir mudança. In: STACEY, Ralph. Pensamento estratégico e gestão de mudança: perspectivas internacionais sobre dinâmica organizacional. Lisboa: Dom Quixote, 1998.

KOTTER, John P. Liderando a mudança: por que fracassam as tentativas de transformação. In: MUDANÇA: Harvard Business Review. Trad. Afonso Celso da Cunha Serra. Rio de janeiro: Campus, 1999.

. Liderando mudança. 3 ed. Rio de Janeiro: Campus, 2000.

Oito erros fatais. In; JÚLIO, Carlos A. Inovação e mudança: autores e conceitos imprescindíveis. São Paulo: Publifolha, 2001.

.What leaders really do. Harvard Business Review, p. 85-96, 2001.

KOTTER, John P; SCHLESINGER, Leonard A. Choosing strategies for change. Harvard Business Review, v. 57, p. 106114, mar./abr. 1979.

MOTOROLA INDUSTRIAL. Site oficial da empresa. Disponível em: <http://www.motorola.com/br.jsp>. Acesso em: 23 mar. 2005.

NADLER, David A., TUSHMAN, Michael L. Beyond the charismatic leader: leadership and organizational change. California Management Review, v. 32, n. 2; p. 77-98, 2001.

PORTUGAL, Ulysses P. Recof e os Ganhos Logísticos. Disponível em < http://www.empresario.com.br/artigos/artigos html/artigo 221003.html>. Acesso em: 22 set. 2005. 
QUATRO, Scott A.; HOEKSTRA, Erik; GILLEY, Jerry W. Holistic model for change agent excellence: core roles and competencies for successful change agency. In: SIMS, Ronald R. Changing the way we manage change. Westport: Quorum Books, 2002.

RICHARDSON, Roberto J. Pesquisa Social: métodos e técnicas. São Paulo: Atlas, 1999.

SALES, José R. R. O novo Recof e as exportações do complexo eletrônico. Informativo Aace, n. 12, maio/jun. 2004.

SENGE, Peter. As cinco disciplina. In: JÚLIO, Carlos A. Inovação e mudança: autores e conceitos imprescindíveis. São Paulo: Publifolha, 2001.

A dança das mudanças : os desafios de manter o crescimento e o sucesso em organizações que aprendem. 7. ed. Rio de janeiro: Campus, 2004.

SIEMENS. Site oficial da empresa. Disponível em: <http://www.siemens.com.br>. Acesso em: 12 abr. 2006.

SIMS, Ronald R. Changing the way we manage change. Westport: Quorum Books, 2002.

SIMS, Ronald; MEA, William. Change management methods in an exciting new world of business-to-business commerce. In: SIMS, Ronald R. Changing the way we manage change. Westport: Quorum Books, 2002.

SIMS, Serbrenia J.; SIMS, Ronald. Employee involvement is still the key to successfully managing change. In: SIMS, Ronald R. Changing the way we manage change. Westport: Quorum Books, 2002.

SMEDS, Ritta. Managing Change towards lean enterprises. International Journal of Operations \& Production Management, v. 14, n. 3, p. 66-82, 1994.

STICKLAND, Francis. Dynamics of change, the: insights into organisational transition from the natural world. London: Routldege, 1998.

TERZIAN, Françoise. Os perigos de mudar. Info Corporate, São Paulo, n. 8, p. 49-59, mar./abr. 2004.

TUSHMAN, Michael L; ANDERSON, Philip. Technological discontinuities and organizational environments. Administrative Science Quarterly, v. 31, p. 439-465, 1986.

VERGARA, Sylvia C. Projetos e relatórios de pesquisa em administração. São Paulo:

Atlas, 2000 